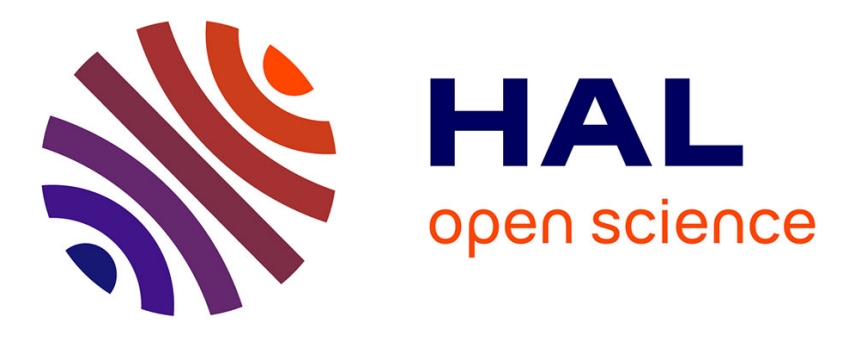

\title{
CD8+T-bet + cells as a predominant biomarker for inclusion body myositis
}

\author{
Gaëlle Dzangué-Tchoupou, Kuberaka Mariampillai, Loïs Bolko, Damien \\ Amelin, Wladimir Mauhin, Aurélien Corneau, Catherine Blanc, Yves \\ Allenbach, Olivier Benveniste
}

\section{To cite this version:}

Gaëlle Dzangué-Tchoupou, Kuberaka Mariampillai, Loïs Bolko, Damien Amelin, Wladimir Mauhin, et al.. CD8+T-bet+ cells as a predominant biomarker for inclusion body myositis. Autoimmunity Reviews, 2019, 18 (4), pp.325-333. 10.1016/j.autrev.2019.02.003 . hal-02534985

\section{HAL Id: hal-02534985 \\ https://hal.sorbonne-universite.fr/hal-02534985}

Submitted on 22 Oct 2021

HAL is a multi-disciplinary open access archive for the deposit and dissemination of scientific research documents, whether they are published or not. The documents may come from teaching and research institutions in France or abroad, or from public or private research centers.
L'archive ouverte pluridisciplinaire HAL, est destinée au dépôt et à la diffusion de documents scientifiques de niveau recherche, publiés ou non, émanant des établissements d'enseignement et de recherche français ou étrangers, des laboratoires publics ou privés.

\section{(ㄷ)(1) $\$$}

Distributed under a Creative Commons Attribution - NonCommerciall 4.0 International 


\section{CD8+ + T-bet+ $_{+}$cells as a predominant biomarker for inclusion body myositis}

Gaëlle Dzangué-Tchoupou $\mathbf{P h D}^{\mathbf{1}^{*}}$, Kuberaka Mariampillai $\mathrm{PhD}^{2}$, Loïs Bolko ${ }^{1}$, Damien Amelin MSc ${ }^{1}$, Wladimir Mauhin MD MSc ${ }^{1}$, Aurélien Corneau $\mathrm{MSc}^{3}$, Catherine Blanc $\mathrm{PhD}^{3}$, Yves Allenbach MD $\mathrm{PhD}^{1,2 \pi}$ Olivier Benveniste $\mathrm{MD} \mathrm{PhD}^{1,2}$

${ }^{1}$ Centre of research in Myology, Sorbonne Université, INSERM, Association Institut de Myologie, UMRS 974, 75013, Paris, France.

${ }^{2}$ Department of Internal medicine and clinical immunology, Pitié-Salpêtrière University hospital, DHU I2B, AP-HP, INSERM, UMR 974, 75103, Paris, France.

${ }^{3}$ Plateforme de Cytométrie (CyPS), Sorbonne Université, UPMC Univ Paris 06, INSERM, UMR 1135, 75013, Paris, France.

*Corresponding author: Gaëlle Dzangué-Tchoupou

Address: 105 Boulevard de l'Hôpital, $3^{\text {rd }}$ floor, Room 318, 75013, Paris, France.

Phone number: (33) 140779684

Fax number: (33) 140778129

E-mail: gaelle.dzangue@gmail.com

Short running title: T-bet: biomarker of inclusion body myositis

Conflicts of interest disclosure: All the authors have no conflicts of interest to disclose. 


\begin{abstract}
Background: Myositis is a heterogeneous group of muscular auto-immune diseases with clinical and pathological criteria that allow the classification of patients into different subgroups. Inclusion body myositis is the most frequent myositis above fifty years of age. Diagnosing inclusion body myositis requires expertise and is challenging. Little is known concerning the pathogenic mechanisms of this disease in which conventional suppressiveimmune therapies are inefficacious.
\end{abstract}

Objectives: Our aim was to deepen our understanding of the immune mechanisms involved in inclusion body myositis and identify specific biomarkers.

Methods: Using a panel of thirty-six markers and mass cytometry, we performed deep immune profiling of peripheral blood cells from inclusion body myositis patients and healthy donors, divided into two cohorts: test and validation cohorts. Potential biomarkers were compared to myositis controls (anti-Jo1-, anti-3-hydroxyl-3-methylglutaryl CoA reductase-, and anti-signal recognition particle-positive patients).

Results: Unsupervised analyses revealed substantial changes only within CD8+ cells. We observed an increase in the frequency of CD8+ cells that expressed high levels of T-bet, and containing mainly both effector and terminally differentiated memory cells. The senescent marker CD57 was overexpressed in CD8+T-bet+ cells of inclusion body myositis patients. As expected, senescent CD8+-bet+ CD57+ cells of both patients and healthy donors were CD28 null $_{\text {CD27 }}$ null CD127 $_{\text {null. }}$ Surprisingly, non-senescent CD8+ ${ }_{\text {T-bet }}$ CD57- cells in inclusion body myositis patients expressed lower levels of CD28, CD27, and CD127, and expressed higher levels of CD38 and HLA-DR compared to healthy donors. Using classification and regression trees alongside receiver operating characteristics curves, we identified and validated a frequency of $\mathrm{CD} 8+$ T-bet+ cells $>51.5 \%$ as a diagnostic biomarker specific to inclusion body myositis, compared to myositis control patients, with a sensitivity of $94.4 \%$, a specificity of $88.5 \%$, and an area under the curve of 0.97 .

Conclusion: Using a panel of thirty-six markers by mass cytometry, we identify an activated cell population (CD8+- - -bet+ $\mathrm{CD} 57-\mathrm{CD} 28_{\text {low }} \mathrm{CD} 27_{\text {low }} \mathrm{CD} 127_{\text {low }} \mathrm{CD} 38+$ HLA-DR+) which could play a role in the physiopathology of inclusion body myositis, and identify CD8+-t-bet+ cells as a predominant biomarker of this disease.

Key words: inclusion body myositis, deep immune profiling, physiopathology, CD8+ T-bet+ cells, biomarkers, myositis 
Abbreviations

CART: classification and regression trees

CI: confidence interval

CTL: cytotoxic T lymphocytes

CyTOF: cytometry by time of flight (mass cytometry)

HD: healthy donors

HLADR: human leukocyte antigen-DR

HMGCR: 3-Hydroxyl-3-MethylGlutaryl CoA Reductase

IdU: iododeoxyuridine

IFN- $\gamma$ : interferon-gamma

IMNM: immune mediated necrotizing myopathies

MMI: median mass intensity

PBMC: peripheral blood mononuclear cells

ROC: receiver operating characteristics

sIBM: sporadic Inclusion body myositis

SPADE: spanning-tree progression analysis of density-normalized events

SRP: signal recognition particle

T-bet: T-box expressed in T cells

TEMRA: terminally differentiated memory cells

viSNE: stochastic neighbor embedding 


\section{Introduction}

Myositis comprises a heterogeneous group of diseases with variable clinical, pathological and serological features, involving both muscular and extra-muscular tissues [1,2]. At present, sporadic inclusion body myositis (sIBM) is the only group bereft of treatment options since there is no evidence of efficacy for corticosteroids and/or immunosuppressive therapies in the long term [3-6]. sIBM is the most common myositis subtype after age 50. Disease onset is slow and progressive, gradually leading to muscle atrophy and a reduced quality of life. Diagnosis at sIBM onset could be misleading, potentially involving administration of a treatment that causes detrimental effects [7].

CD8+ $\mathrm{T}$ cells have been implicated in the physiopathology of sIBM because of their aggressive and infiltrative presence within muscle fibres overexpressing major histocompatibility type 1 molecules [8-12]. Various studies have observed a diverse repertoire of CD8+ $\mathrm{T}$ cells in the peripheral blood of sIBM patients, suggesting the presence of antigen-driven CD8+ T cell responses [13-15].

Two major T-box transcription factors drive differentiation of naïve CD8+ T cells into cytolytic T lymphocytes (CTL): T-bet (T-box expressed in T cells) and eomesodermin (eomes) $[16,17]$. High levels of T-bet expression in CD8+ $\mathrm{T}$ cells are required for antigenspecific CD8+ response, cytotoxic function and maintenance of memory subsets [18-21].

Repeated and prolonged stimulation of $\mathrm{T}$ cells leads to progressive loss of costimulatory markers, such as CD28 and CD27. Downregulation of the interleukin-7 alpha receptor (CD127) is also observed following chronic antigen stimulation [22,23]. In addition to this immune profile, expression of CD57 defines a state of replicative senescence [24-27].

B cell implication in the pathogenicity of sIBM has been suggested by the identification of anti-cytosolic 5'-nucleotidase 1A antibodies present in $\sim 30 \%$ of patients [28-30]. Plasma cells are also observed in muscle inflammatory infiltrates of sIBM [31]. Finally, muscle biopsies from sIBM patients also reveal the presence of macrophages infiltrating non-necrotic muscle fibres [32], suggesting the involvement of innate immune defence mechanisms that are still poorly investigated.

Cytometry by time of flight (CyTOF), also known as mass cytometry, is an innovative cell profiling tool based on antigen detection using metal-conjugated antibodies. CyTOF allows simultaneous screening of more than 38 markers at the single cell level [33,34]. CyTOF is of particular interest in applications of deep immune profiling and biomarker 


\section{Introduction}

discovery. When using CyTOF, intra-assay variations can be reduced by barcoding cells prior to staining for markers [35-37].

Considering the detrimental effects of immunosuppressants prescribed due to misdiagnosis, there is a need to identify novel diagnostic biomarkers for sIBM and to better understand the pathogenic mechanisms involved in this disease. The aim of this study was to better characterize the phenotype of peripheral blood mononuclear cells (PBMCs) from sIBM patients, to identify cells potentially involved in the pathophysiology of the disease and to identify a biomarker that can aid in the rapid diagnosis of sIBM from other types of myositis. 


\section{Material and methods}

\subsection{Patients and samples:}

Approval for this study was obtained from the Comité Consultatif sur le Traitement de l'Information en matière de la Recherche dans le domaine de la Santé (CCTIRS), France. Written informed consent was signed by all patients and age-matched healthy donors (HD) according to the declaration of Helsinki. Untreated sIBM patients (cohort 1, n=10 and cohort 2, $n=8$ ) were defined based on the Lloyd diagnosis criteria [38]. Control groups of active myositis patients included untreated myositis patients suffering from anti-synthetase syndrome with anti-Jo1 positive antibodies (anti-Jo1, n=10), anti-3-hydroxyl-3-methylglutaryl CoA reductase positive immune mediated necrotizing myopathy (anti-HMGCR IMNM, n=9) and anti-signal recognition particle positive IMNM (anti-SRP IMNM, n=7) defined based on published ENMC criteria [39,40]. Main characteristics of patients are described in Supplementary Table 1. Detection of myositis-specific antibodies was performed by immunoassays as previously described [41]. Healthy control blood samples were obtained from the Etablissement Français du sang (EFS, Pitié-Salpêtrière-France) donated by healthy adults age-matched with sIBM patients (cohort $1, \mathrm{n}=8$ and cohort $2, \mathrm{n}=8$ ).

Upon reception of blood samples, peripheral blood mononuclear cells (PBMCs) were isolated and stored at $-80^{\circ} \mathrm{C}$ in foetal bovine serum (Life Technologies, Saint-Aubin, France, Catalogue \# 10270106) supplemented with 10\% dimethyl sulfoxide. Twenty-four hours later, the cells were transferred to liquid nitrogen until use.

\subsection{Mass cytometry experiments:}

Thirty-six metal-conjugated antibodies, viability staining, and Iododeoxyuridine (IdU) were obtained from Fluidigm (Les Ulis, France) (Supplementary Table 2). Immunostaining and data acquisition were performed as previously described in a technical research article [36]. Briefly, PBMCs were incubated with IdU and then stained with cisplatin. Next, cells were incubated with CCR7 and CXCR5, followed by incubation with a mix containing all other cell surface markers. Next, samples were barcoded using BD CyTOFix/Cytoperm and BD wash/perm buffer (BD, France, Catalogue \# 554715). All cells from different samples were washed and pooled together in a single tube. Fixation of pooled cells was performed using BD CyTOFix/Cytoperm buffer followed by incubation with antibodies targeting intranuclear markers in BD wash/perm buffer. Finally, DNA within cells was labelled using Cell ID Intercalator-Ir (Fluidigm, les Ulis, France, Catalogue \# 201192A). Cellular events 


\section{Material and methods}

were acquired the following day on the Helios available at the "Plateforme de Cytométrie de la Pitié-Salpêtrière”.

Data files were obtained in the FCS file format and analysed using different algorithms available on the Cytobank cloud based platform, $\mathrm{R}$ software version 3.4.0 and GraphPad Prism version 6.

\subsection{Data analysis:}

Beads were gated out using the following: 140/142Ce, 151/153Eu, $165 \mathrm{Ho}$ and 175/176 Lu. Cisplatin-positive dead cells were gated out, and automated identification of stratifying signatures in cellular populations was performed using the Citrus algorithm to identify differences between sIBM patients and healthy donors. We performed Citrus analyses using the median mass intensities (MMI) of various markers. The settings used for Citrus were as follows: population (all CD45+ cells), groups (Healthy donors and sIBM patients), clustering channels (CD19, CD56, CD11b, CD14, CD3, CD4, CD8, CD25, CD45RA, CCR7), statistics channels (HLA-DR, IgD, CD28, CD127, CD27, T-bet, FoxP3, CD38, CD57), equal event sampling (20000 each), minimum cluster size (5\%), cross validation fold (5) and false discovery rate $(1 \%)$.

Next, using the cytobank cloud based platform, automated cell clustering using spanning-tree progression analysis of density-normalized events (SPADE) was performed on CD45+ events. This is to allow a non-biased and uniform gating strategy of the main cell populations in our study. The SPADE tree was generated based on main phenotypic markers such as: CD3, CD4, CD8, CD14, CD11b, CD56, CD16 and CD19, with 20 nodes and a down-sampling of 10 percent. Nodes corresponding to homogenous cell populations were each exported to a new experiment.

Next, we used stochastic neighbour embedding (viSNE) to explore detail populations of interest with an unbiased approach. The settings used for the viSNE run on CD8+ T cells are as follows: equal event sampling (3615 each), channels (CD28, CD127, CD27, T-bet and CD57), iterations (1000), perplexity (50) and theta (0.3). Furthermore, we analysed the frequency of various cell populations and the MMI of various markers on the subsets obtained from the viSNE run.

Histograms and dot plots were used to confirm all results obtained from unsupervised analyses. 


\section{Material and methods}

For identification of biomarkers specific to sIBM patients (cohort 1 and $2, n=18$ ) compared to control myositis patients (anti-Jo1, anti-SRP and anti-HMGCR, n=26), we constructed a decisional tree using classification and regression trees (CART) with $\mathrm{R}$ software. As a result, new subjects from different subgroups can be predicted using a ranking algorithm. We included in the CART "potential predictors" based on our previous observations: frequencies of CD8+ T-bet+ T cells, CD8+ T-bet+ CD57+ T cells, CD8+ Tbet+ CD27+ T cells, CD8+ T-bet+ CD57+ CD27+ T cells and CD8+ T-bet+ CD57- CD27+ T cells. The validity of our classification tree model and the predictors (biomarkers) were validated by cross validation on a test set.

Using GraphPad Prism, we performed receiver operating characteristic (ROC) curves to better describe the biomarkers identified. Altogether, we chose a prediction value associated with the best cross-validation prediction rate on the test set using CART and with the best sensitivity, specificity, confidence interval (CI), and area under the curve (AUC) and a p-value $<0.0001$ with ROC curves.

We used Shapiro-Wilk normality test to verify the distribution of quantitative data among the groups compared. For comparison of two groups, we used either the MannWhitney test or the t-test. When comparing MMI of expression for a marker within a population, we used the t-test. For multiple comparisons, we used the Kruskal-Wallis test using the Geisser-Greenhouse correction. We describe in-text data values using mean \pm SD. 


\section{Results}

\subsection{Increased frequency of CD8+ $\mathrm{T}$ cells in sIBM patients expressing high levels of T-bet and presenting a senescent immune profile (CD8T-bet+ CD57+):}

Mean age of sIBM patients was $63.8 \pm 2$ and $61 \pm 1$ for healthy donors $(p=0.152)$. To identify biomarkers specific to sIBM, we performed automated identification of stratifying signatures in CD45+ cellular populations using the Citrus algorithm. This analysis aimed to identify markers that vary significantly between sIBM patients (cohort $1, n=10$ ) and healthy donors (cohort $1, \mathrm{n}=8$ ). Citrus did not identify any significant differences in activation or differentiation markers within B cells, CD16 \pm CD $56^{\text {bright }} \mathrm{NK}$ cells, CD16+CD56 ${ }^{\mathrm{dim}} \mathrm{NK}$ cells, monocytes, CD4+ T cells or CD38+ cells (Fig. 1). These observations were confirmed by classical gating of individual populations. Interestingly, significant differences were observed only within $\mathrm{CD} 8+\mathrm{T}$ cell populations regarding the expression of $\mathrm{CD} 27, \mathrm{CD} 57, \mathrm{CD} 127$, CD28, T-bet and CD38. We next decided to characterize in detail CD8+ $\mathrm{T}$ cells in sIBM patients.

CD3+ CD8+ events corresponding to CD8+ $\mathrm{T}$ cells from the SPADE run on all CD45+ events were exported for further analysis (Supplementary Fig. 1). First, we observed a significant increase in the frequency of CD8+ T-bet+ $\mathrm{T}$ cells (CD8 $\left.{ }^{-b e t+}\right)$ in sIBM patients compared to healthy donors $[\mathrm{sIBM}=75.5 \% \pm 13.2, \mathrm{HD}=57.4 \% \pm 15.2, \mathrm{p}=0.02]$. Further analysis revealed a remarkable increase in the frequency of $\mathrm{CD} 8+$ terminally differentiated memory $\mathrm{T}$ cells (TEMRA): CD8+ CD45RA+ CCR7- in patients [sIBM=51.9\% $\pm 13.6, \mathrm{HD}=19.1 \% \pm 9.9$, p <0.0001] (Fig. 2). Interestingly CD8T-bet+ cells contain mainly both effector memory (EM) and TEMRA cells [\% EM: sIBM=27\% $\pm 16.4, \mathrm{HD}=56 \% \pm 12.1, \mathrm{p}=0.0008$ and $\%$ TEMRA: $\mathrm{sIBM}=66.1 \% \pm 16.8, \quad \mathrm{HD}=30.4 \% \pm 13.3, \mathrm{p}=0.0002]$ (Supplementary Fig. 2). Next, we compared the expression of the senescence marker CD57 within CD8 ${ }_{\text {T-bet+ }}$ cells and CD8+ Tbet- events $\left(\mathrm{CD} 8_{\text {T-bet- }}\right.$ cells). We observed a marked increase in the expression of CD57 within CD8 ${ }_{\text {T-bet+ }}$ cells in sIBM patients, while healthy donors had very low expression of CD57 in both CD8 ${ }_{\text {T-bet+ }}$ cells and CD8 ${ }_{\text {T-bet- }}$ cells [MMI of CD57 in CD8 ${ }_{\text {T-bet+ }}$ cells: sIBM=188, HD=6, $\mathrm{p}=0.01$ and MMI of CD57 in CD8T-bet- cells: sIBM=0.4, HD=0.08, $\mathrm{p}=0.09$ ] (Supplementary Fig. 3).

3.2.Selective loss of $\mathrm{CD28}, \mathrm{CD} 27$ and $\mathrm{CD127}$ in non-senescent CD8+ $\mathrm{T}$ cells

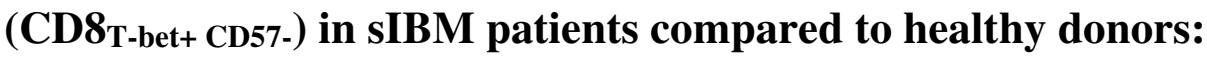




\section{Results}

Next, we focused on three main subsets of CD8+ T cells of interest: senescent CD8 ${ }_{\text {T-bet+ }}$ CD57+ cells, non-senescent CD8 ${ }_{\text {T-bet+ }}$ CD57- cells and Naive CD8 ${ }_{\text {T-bet- cells. We compared }}$ expression of the co-stimulatory markers CD28 and CD27 and the functional marker CD127 within these three subsets. As expected, senescent CD8 $8_{-b e t+}$ CD57+ cells are CD28null CD27null CD127null in both patients and healthy donors (Supplementary Fig. 4). Unexpectedly, we observed a decrease in expression of CD28, CD27 and CD127 in nonsenescent CD8T-bet+ CD57- cells of sIBM patients compared to healthy donors. Loss of CD28, CD27 and CD127 was not observed in CD8 ${ }_{\text {T-bet- }}$ cells of either patients or healthy donors (Fig. 3).

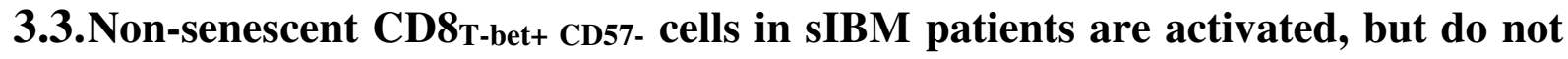 spontaneously secrete greater amounts of IFN- $\gamma$ :}

Observation of this particular memory immune profile in non-senescent CD8 ${ }_{\text {T-bet+ }}$ CD57cells in sIBM patients prompted us to explore their activation states in comparison to other subsets we had examined. We compared the frequency of our populations of interest expressing activation markers CD38 and HLA-DR (Human Leucocyte Antigen-DR). Spontaneous interferon-gamma (IFN- $\gamma$ ) was also quantified. Interestingly, we observed higher

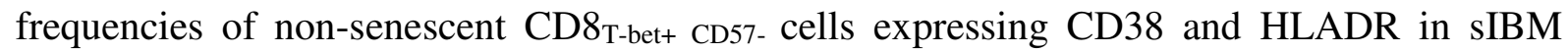
patients compared to healthy donors [HLADR+ cells: sIBM=9.9\% $\pm 6.2, \mathrm{HD}=4.6 \% \pm 2.2$, $\mathrm{p}=0.04$ and $\mathrm{CD} 38+$ cells: $\mathrm{sIBM}=24.5 \% \pm 17.3, \mathrm{HD}=9 \% \pm 5, \mathrm{p}=0.02]$. An increase in the

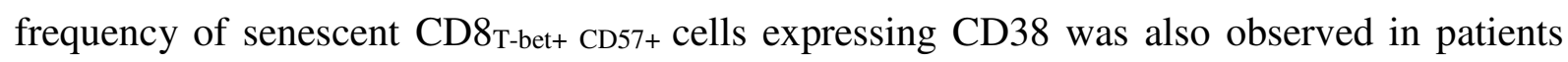
[CD38+ cells: $\mathrm{sIBM}=34.4 \% \pm 9, \mathrm{HD}=4 \% \pm 1.1, \mathrm{p}=0.0005]$. We did not observe changes in spontaneous IFN- $\gamma$ secretion between sIBM patients and healthy donors (Fig. 4). Low percentages of CD8T-bet- cells expressing CD8 and HLADR were similarly observed in both patients and healthy donors (Supplementary Fig. 5)

\subsection{Confirmation of observed characteristics in a second independent cohort of sIBM patients:}

In an attempt to validate the immune profiles we observed in the first cohort of sIBM patients $(\mathrm{n}=10)$, we stained PBMCs from a second independent cohort with a minimal set of markers using an independent experiment (cohort 2 : sIBM=8 and healthy donors=8). We confirmed increased frequencies of TEMRA CD8+ T cells, CD8T-bet+ cells and activated nonsenescent $\mathrm{CD} 8_{\mathrm{T}-\mathrm{bet}} \mathrm{CD} 57$ - cells in SIBM patients from cohort 2 in comparison to healthy 


\section{Results}

donors. A non-significant tendency towards higher frequencies of CD38+ senescent CD8 $8_{\text {T-bet+ }}$ CD57+ cells was observed. We also confirmed lower expression of CD27, CD127 and CD28 by

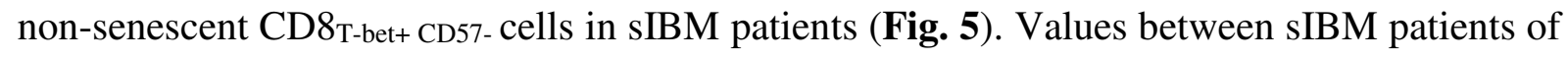
cohort 1 and 2 were not significantly different with respect to immune profile (Supplementary Fig. 6).

Taken together, these observations describe a novel increase in the frequency of senescent CD8 1 -bet+ CD57+ cells in sIBM patients compared to healthy donors. Further, sIBM patients exhibit an activated non-senescent $\mathrm{CD} 8+_{\mathrm{T}-\text { bet }}$ CD57- cell population characterized by lower expression of CD28, CD27 and CD127, and higher expression of CD38 and HLADR compared to healthy donors.

\subsection{Identification of biomarkers specific to sIBM patients:}

. Next, we aimed to identify a minimal set of biomarkers that can be used as diagnostic criteria for sIBM patients (cohort 1 and 2, n=18). Other myositis patients presenting either anti-Jo1 auto-antibodies, anti-SRP auto-antibodies or anti-HMGCR auto-antibodies were used as controls. After multiple CART runs using different predictors, such as the frequency of

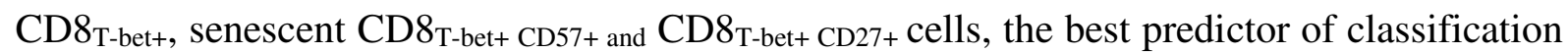
was always the frequency of CD8 ${ }_{\text {T-bet+ }}$ cells. Given that the cut-off prediction frequency of CD8 $8_{\text {T-bet+ }}$ cells could vary between different CART runs, we used ROC curves to help choose the best predictive value. Altogether, using CART and ROC curves, we identified and validated a frequency of CD8 ${ }_{\text {T-bet+ }}$ cells $>51.51 \%$ as the best predictor to distinguish SIBM patients from other myositis patients $(n=26)$, with a sensitivity of $94.4 \%$, a specificity of $88.5 \%$, a confidence interval of [69.9-97.6\%], an area under curve of 0.97 and a p-value < 0.0001 (Fig. 6). 


\section{Discussion}

Using CyTOF, we simultaneously analysed thirty-six markers on non-stimulated PBMCs from sIBM patients and healthy donors. Unsupervised analysis revealed significant changes only within CD8+ T cells. CD8+ T cells from sIBM patients overexpress T-bet. Loss of CD28, CD27 and CD127 in senescent CD8 ${ }_{\text {T-bet+ }}$ CD57+ cells in both sIBM patients and healthy donors was expected. Unexpectedly, we observed specific loss of CD28, CD27 and CD127 in non-senescent CD8 ${ }_{\text {T-bet+ }}$ CD57- cells from sIBM patients but not from healthy subjects.

Previous studies have demonstrated that during chronic antigen stimulation, overexpression of T-bet on CD8+ $\mathrm{T}$ cells represses expression of inhibitory receptors, defining a subset of exhausted CD8+ T cells with proliferative capacity and effector functions (21)]. In this study we identified a subset of activated non-senescent CD8+ T-be+ cells defined by low levels of expression of CD57 and higher levels of expression of CD38 and HLA-DR in sIBM patients compared to healthy donors. This activated and non-senescent immune profile suggests continuous proliferative capacity and effector functions of these cells in sIBM patients, which could explain the progressive and destructive nature of sIBM. This suggestion is supported by the presence of not only TEMRA, but also EM cells within T-bet+ cells of sIBM patients.

Our results are in line with previous studies that observed increased frequencies of CD8+ CD28null T cells in PBMCs from sIBM patients compared to healthy individuals (15). More recently, CD8+ CD57+ large granular lymphocytes were observed in blood and muscle of sIBM patients (14)]. Here, we present a more detailed and precise phenotype of peripheral blood CD8+ T cells in sIBM patients, thus enhancing understanding of this disease.

In this study, we did not observe an increase in spontaneous IFN- $\gamma$ secretion by CD8Tbet+ cells from sIBM patients. This could be because cells were not stimulated, since our aim was to gain insight into the immune profile of PBMCs from sIBM patients without stimulation. We previously showed an increase in IFN- $\gamma$ secretion by PBMC in sIBM patients after stimulation (13)].

In this study, we were also able to identify a novel diagnostic biomarker for IBM. Various diagnostic criteria for sIBM have been described, with sensitivities ranging from $11 \%$ to $90 \%$ and specificities above $96 \%$ (38)]. Compared to other myositis subtypes (anti-Jo1 positive antibodies, IMNM with anti-HMGCR positive and anti-SRP positive antibodies), we 


\section{Discussion}

obtained the highest sensitivity described thus far (sensitivity of 94.4\%), and 88.5\% specificity. All previous diagnostic criteria combined clinical and pathological analyses, both of which require specific expertise. The biomarker we present herein is based on two biological markers (CD8 and T-bet), and could be complementary to the actual diagnostic approaches used for sIBM patients. This biomarker could aid in categorizing patients for clinical trials and research, especially when diagnosis remains uncertain. Further prospective analyses are needed to compare this novel biological biomarker to pathological criteria in patients with IBM suspicion. 


\section{Funding source}

This research did not receive any specific grant from funding agencies in the public, commercial, or not-for-profit sectors. 


\section{Competing interests}

All the authors have no conflicts of interest to disclose. 


\section{Supplementary material}

Supplementary Table 1: Clinical characteristics of active sIBM and myositis control patients Supplementary Table 2: List of antibodies

Supplementary Fig 1: Automated cell clustering using the SPADE algorithm

Supplementary Fig 2: Distribution of CD8 cell populations within CD8+ T-bet+ cells Supplementary Fig 3: Expression of CD57 in CD8+ T cells

Supplementary Fig 4: Expression of CD28, CD27 and CD127 in senescent CD8 cells

Supplementary Fig 5: Frequency of cells expressing activation markers

Supplementary Fig 6: Close values for the immune profiles of sIBM patients from cohort 1 and cohort 2 


\section{References}

[1] Gao S, Luo H, Zhang H, Zuo X, Wang L, Zhu H. Using multi-omics methods to understand dermatomyositis/polymyositis. Autoimmun Rev. 2017 Oct;16(10):1044-8.

[2] Suzuki S, Uruha A, Suzuki N, Nishino I. Integrated Diagnosis Project for Inflammatory Myopathies: An association between autoantibodies and muscle pathology. Autoimmun Rev. 2017 Jul;16(7):693-700.

[3] Dalakas MC. Sporadic inclusion body myositis--diagnosis, pathogenesis and therapeutic strategies. Nat Clin Pract Neurol. 2006 Aug;2(8):437-47.

[4] Needham M, Mastaglia FL. Sporadic inclusion body myositis: A review of recent clinical advances and current approaches to diagnosis and treatment. Clin Neurophysiol Off J Int Fed Clin Neurophysiol. 2016 Mar;127(3):1764-73.

[5] Keller CW, Schmidt J, Lünemann JD. Immune and myodegenerative pathomechanisms in inclusion body myositis. Ann Clin Transl Neurol. 2017 Jun;4(6):422-45.

[6] Cavagna L, Monti S, Caporali R, Gatto M, Iaccarino L, Doria A. How I treat idiopathic patients with inflammatory myopathies in the clinical practice. Autoimmun Rev. 2017 Oct;16(10):9991007.

[7] Benveniste O, Guiguet M, Freebody J, Dubourg O, Squier W, Maisonobe T, et al. Long-term observational study of sporadic inclusion body myositis. Brain J Neurol. 2011 Nov;134(Pt 11):3176-84.

[8] Benveniste O, Stenzel W, Hilton-Jones D, Sandri M, Boyer O, van Engelen BGM. Amyloid deposits and inflammatory infiltrates in sporadic inclusion body myositis: the inflammatory egg comes before the degenerative chicken. Acta Neuropathol (Berl). 2015 May;129(5):611-24.

[9] Müntzing K, Lindberg C, Moslemi A-R, Oldfors A. Inclusion body myositis: clonal expansions of muscle-infiltrating T cells persist over time. Scand J Immunol. 2003 Aug;58(2):195-200.

[10] Salajegheh M, Rakocevic G, Raju R, Shatunov A, Goldfarb LG, Dalakas MC. T cell receptor profiling in muscle and blood lymphocytes in sporadic inclusion body myositis. Neurology. 2007 Oct 23;69(17):1672-9.

[11] Day J, Otto S, Proudman S, Hayball JD, Limaye V. Dysregulated innate immune function in the aetiopathogenesis of idiopathic inflammatory myopathies. Autoimmun Rev. 2017 Jan;16(1):8795.

[12] Afzali AM, Müntefering T, Wiendl H, Meuth SG, Ruck T. Skeletal muscle cells actively shape (auto)immune responses. Autoimmun Rev. 2018 May;17(5):518-29.

[13] Allenbach Y, Chaara W, Rosenzwajg M, Six A, Prevel N, Mingozzi F, et al. Th1 response and systemic treg deficiency in inclusion body myositis. PloS One. 2014;9(3):e88788.

[14] Greenberg SA, Pinkus JL, Amato AA, Kristensen T, Dorfman DM. Association of inclusion body myositis with T cell large granular lymphocytic leukaemia. Brain J Neurol. 2016;139(Pt 5):1348-60.

[15] Pandya JM, Fasth AER, Zong M, Arnardottir S, Dani L, Lindroos E, et al. Expanded T cell receptor $\mathrm{V} \beta$-restricted $\mathrm{T}$ cells from patients with sporadic inclusion body myositis are proinflammatory and cytotoxic CD28null T cells. Arthritis Rheum. 2010 Nov;62(11):3457-66. 


\section{References}

[16] McLane LM, Banerjee PP, Cosma GL, Makedonas G, Wherry EJ, Orange JS, et al. Differential localization of T-bet and Eomes in CD8 T cell memory populations. J Immunol Baltim Md 1950. 2013 Apr 1;190(7):3207-15.

[17] Knox JJ, Cosma GL, Betts MR, McLane LM. Characterization of T-Bet and Eomes in Peripheral Human Immune Cells. Front Immunol [Internet]. 2014 May 14 [cited 2017 Mar 3];5. Available from: http://www.ncbi.nlm.nih.gov/pmc/articles/PMC4030168/

[18] Wherry EJ, Kurachi M. Molecular and cellular insights into T cell exhaustion. Nat Rev Immunol. 2015 Aug;15(8):486-99.

[19] Paley MA, Kroy DC, Odorizzi PM, Johnnidis JB, Dolfi DV, Barnett BE, et al. Progenitor and terminal subsets of CD8+ T cells cooperate to contain chronic viral infection. Science. 2012 Nov 30;338(6111):1220-5.

[20] Blackburn SD, Shin H, Freeman GJ, Wherry EJ. Selective expansion of a subset of exhausted CD8 T cells by alphaPD-L1 blockade. Proc Natl Acad Sci U S A. 2008 Sep 30;105(39):1501621.

[21] Kao C, Oestreich KJ, Paley MA, Crawford A, Angelosanto JM, Ali M-AA, et al. Transcription factor T-bet represses expression of the inhibitory receptor PD-1 and sustains virus-specific CD8+ T cell responses during chronic infection. Nat Immunol. 2011 May 29;12(7):663-71.

[22] Xu W, Li J, Wu Y, Zhou J, Zhong J, Lv Q, et al. CD127 Expression in Naive and Memory T Cells in HIV Patients Who Have Undergone Long-Term HAART. Lab Med. 2017 Feb 1;48(1):57-64.

[23] Kared H, Saeed S, Klein MB, Shoukry NH. CD127 expression, exhaustion status and antigen specific proliferation predict sustained virologic response to IFN in HCV/HIV co-infected individuals. PloS One. 2014;9(7):e101441.

[24] Brenchley JM, Karandikar NJ, Betts MR, Ambrozak DR, Hill BJ, Crotty LE, et al. Expression of CD57 defines replicative senescence and antigen-induced apoptotic death of CD8+ T cells. Blood. 2003 Apr 1;101(7):2711-20.

[25] Appay V, Dunbar PR, Callan M, Klenerman P, Gillespie GMA, Papagno L, et al. Memory CD8+ T cells vary in differentiation phenotype in different persistent virus infections. Nat Med. 2002 Apr;8(4):379-85.

[26] Olson JA, McDonald-Hyman C, Jameson SC, Hamilton SE. Effector-like CD8+ T cells in the memory population mediate potent protective immunity. Immunity. 2013 Jun 27;38(6):1250-60.

[27] Hendriks J, Xiao Y, Borst J. CD27 promotes survival of activated T cells and complements CD28 in generation and establishment of the effector T cell pool. J Exp Med. 2003 Nov 3;198(9):1369-80.

[28] Pluk H, van Hoeve BJA, van Dooren SHJ, Stammen-Vogelzangs J, van der Heijden A, Schelhaas HJ, et al. Autoantibodies to cytosolic 5'-nucleotidase 1A in inclusion body myositis. Ann Neurol. 2013 Mar;73(3):397-407.

[29] Larman HB, Salajegheh M, Nazareno R, Lam T, Sauld J, Steen H, et al. Cytosolic 5'nucleotidase 1A autoimmunity in sporadic inclusion body myositis. Ann Neurol. 2013 Mar;73(3):408-18.

[30] Benveniste O, Stenzel W, Allenbach Y. Advances in serological diagnostics of inflammatory myopathies. Curr Opin Neurol. 2016;29(5):662-73. 


\section{References}

[31] Greenberg SA, Bradshaw EM, Pinkus JL, Pinkus GS, Burleson T, Due B, et al. Plasma cells in muscle in inclusion body myositis and polymyositis. Neurology. 2005 Dec 13;65(11):1782-7.

[32] Rygiel KA, Miller J, Grady JP, Rocha MC, Taylor RW, Turnbull DM. Mitochondrial and inflammatory changes in sporadic inclusion body myositis. Neuropathol Appl Neurobiol. 2015 Apr;41(3):288-303.

[33] Bendall SC, Simonds EF, Qiu P, Amir el-A, Krutzik PO, Finck R, et al. Single-cell mass cytometry of differential immune and drug responses across a human hematopoietic continuum. Science. 2011 May;332(6030):687-96.

[34] Behbehani GK, Samusik N, Bjornson ZB, Fantl WJ, Medeiros BC, Nolan GP. Mass Cytometric Functional Profiling of Acute Myeloid Leukemia Defines Cell-Cycle and Immunophenotypic Properties That Correlate with Known Responses to Therapy. Cancer Discov. 2015 Sep;5(9):988-1003.

[35] Zunder ER, Finck R, Behbehani GK, Amir E-AD, Krishnaswamy S, Gonzalez VD, et al. Palladium-based mass tag cell barcoding with a doublet-filtering scheme and single-cell deconvolution algorithm. Nat Protoc. 2015 Feb;10(2):316-33.

[36] Dzangué-Tchoupou G, Corneau A, Blanc C, Benveniste O, Allenbach Y. Analysis of cell surface and intranuclear markers on non-stimulated human PBMC using mass cytometry. PloS One. 2018;13(3):e0194593.

[37] Behbehani GK, Thom C, Zunder ER, Finck R, Gaudilliere B, Fragiadakis GK, et al. Transient partial permeabilization with saponin enables cellular barcoding prior to surface marker staining. Cytom Part J Int Soc Anal Cytol. 2014 Dec;85(12):1011-9.

[38] Lloyd TE, Mammen AL, Amato AA, Weiss MD, Needham M, Greenberg SA. Evaluation and construction of diagnostic criteria for inclusion body myositis. Neurology. 2014 Jul 29;83(5):426-33.

[39] Hoogendijk JE, Amato AA, Lecky BR, Choy EH, Lundberg IE, Rose MR, et al. 119th ENMC international workshop: trial design in adult idiopathic inflammatory myopathies, with the exception of inclusion body myositis, 10-12 October 2003, Naarden, The Netherlands. Neuromuscul Disord NMD. 2004 May;14(5):337-45.

[40] Allenbach Y, Mammen AL, Benveniste O, Stenzel W, Immune-Mediated Necrotizing Myopathies Working Group. 224th ENMC International Workshop:: Clinico-sero-pathological classification of immune-mediated necrotizing myopathies Zandvoort, The Netherlands, 14-16 October 2016. Neuromuscul Disord NMD. 2018 Jan;28(1):87-99.

[41] Arouche-Delaperche L, Allenbach Y, Amelin D, Preusse C, Mouly V, Mauhin W, et al. Pathogenic role of anti-signal recognition protein and anti-3-Hydroxy-3-methylglutaryl-CoA reductase antibodies in necrotizing myopathies: Myofiber atrophy and impairment of muscle regeneration in necrotizing autoimmune myopathies. Ann Neurol. 2017 Apr;81(4):538-48. 


\section{Figure captions}

Fig 1: Automated identification of stratifying signatures in cellular populations between patients and healthy donors (use of median mass intensities)

Cells from sIBM patients (cohort $1, n=10)$ and age-matched healthy donors $(n=8)$ were labeled individually with antibodies targeting cell surface antigens. Next, the cells were barcoded, pooled and labelled with antibodies targeting intranuclear antigens. Beads and dead cells were gated out. Automated identification of stratifying signatures in cellular populations was performed using the Citrus algorithm available on the Cytobank cloud-based platform. The settings used for the Citrus runs on total cells were as follow: population (all CD45+ cells), groups (Healthy donors and sIBM patients), clustering channels (CD3, CD4, CD8, CD11b, CD56, CD19, CD25, CD45RA and CCR7), statistics channels (HLA-DR, IgD, CD28, CD127, FoxP3, CD27, CD38, T-bet and CD57), equal event sampling (20.000 events each), minimum cluster size (5\%), cross validation fold (5) and false discovery rate (1\%). a) Clustering channels, b) shows the model error rate of the output classification models and c) markers which vary significantly between sIBM patients and HD within the colored nodes.

Fig 2: Increase frequency of $\mathrm{CD8}+\mathrm{T}$ cells in sIBM patients expressing high levels of $\mathrm{T}$ bet and presenting a senescent immune profile (T-bet+ CD57+)

Cells from sIBM patients (cohort $1, \mathrm{n}=10)$ and healthy donors $(\mathrm{n}=8)$ were labeled individually with antibodies targeting cell surface antigens. Next, the cells were barcoded, pooled and labelled with antibodies targeting intranuclear antigens. Automated cell clustering was performed using the SPADE and viSNE algorithms available on the cytobank cloud-based platform. Here, we describe detail observations on CD8+ T cells: a) frequency of T-bet+ cells in a patient and a healthy individual, b) visualization of different CD8+ T cell populations, $\mathbf{c}$ and d) comparison of the percentages of T-bet+ and TEMRA cells respectively, between sIBM patients and healthy donors. Two-tailed statistical analyses were performed using Mann-Whitney test $\left({ }^{*} \mathrm{p}<0.05, * * \mathrm{p}<0.001, * * * \mathrm{p}<0.0001\right.$ and $\left.* * * * \mathrm{p}<0.00001\right)$. The data shown are representative of an independent experiment and represent median with interquartile.

Fig 3: Selective loss of CD28, CD27 and CD127 in non-senescent CD8+ T cells $\left(\mathrm{CD}_{\mathrm{T}}\right.$-bet+ CD57-) in SIBM patients compared to healthy donors

Data correspond to sIBM patients and healthy donors of cohort 1 . We defined three populations of CD8+ T cells based on the expression of T-bet and CD57: naive (CD8+ T-bet), senescent (CD8+ T-bet+ CD57+) and non-senescent (CD8+ T-bet+ CD57-) CD8 cells. a) 


\section{Figure captions}

dot plot showing the expression of CD57 amongst CD8+ T-bet+ cells of an individual, b) heat maps showing the median mass intensity (MMI) of CD28, CD27 and CD127 and c) comparison of the MMI of CD28, CD27 and CD127 between sIBM patients and HD. Twotailed statistical analyses were performed using t-test $(* \mathrm{p}<0.05, * * \mathrm{p}<0.001, * * * \mathrm{p}<0.0001$ and $* * * * p<0.00001)$. The data shown are representative of an independent experiment and represent median with interquartile.

Fig 4: Non-senescent CD8+ cells in sIBM patients show an activated immune profile; nevertheless they do not spontaneously secrete greater amounts of IFN- $\gamma$

Data correspond to sIBM patients and healthy donors of cohort 1. Automated cell clustering was performed using the viSNE algorithm available on the cytobank cloud-based platform. The settings used for the viSNE run on CD8+ T cells were as follow: equal event sampling (3615 events each), channels (CD28, CD127, CD27, T-bet and CD57), iterations (1000), perplexity (50) and theta (0.3). Each dot represents a cell and each viSNE map is representative of a single subject. ViSNE maps show the single cell expression of a) CD38, b) HLADR and c) IFNg. Next, we compared the frequencies of cells expressing activation markers in different populations between sIBM patients and HD: d) comparison of the percentages of CD38+ cells, e) HLA-DR+ cells and f) IFNg+ cells. Two-tailed statistical analyses were performed using Mann-Whitney test $(* \mathrm{p}<0.05, * * \mathrm{p}<0.001, * * * \mathrm{p}<0.0001$ and $* * * * p<0.00001)$. The data shown are representative of an independent experiment and represent median with interquartile.

Fig 5: Confirmation of the immune profile identified using an independent cohort of sIBM patients and healthy donors

In order to confirm the immune profile of sIBM in comparison to healthy donors, we used an independent mass cytometry experiment and different subjects. Cells from sIBM patients (cohort $2, n=8)$ and healthy donors $(n=8)$ were labeled individually with antibodies targeting cell surface antigens. Next, the cells were barcoded, pooled and labelled with antibodies targeting intranuclear antigens. Automated cell clustering was performed using the SPADE algorithm available on the cytobank cloud-based platform. CD8+ T cells were exported for downstream analyses. a) frequency of T-bet+ cells, b) frequency of TEMRA cells, c) frequency of CD38+ and HLADR+ non-senescent CD8 cells and e) MMI of CD28, CD27 and CD127 in non-senescent CD8 cells. Two-tailed statistical analyses were performed using either t-test or Mann-Whitney (depending on normality test) to compare either the percentages 


\section{Figure captions}

or the MMI $\left({ }^{*} \mathrm{p} \leq 0.05\right)$. The data shown are representative of an independent experiment and represent median with interquartile.

\section{Fig 6: Identification of biomarkers specific to sIBM patients in comparison to control} myositis patients

In order to identify biomarkers specific to SIBM patients (cohort 1 and 2, $n=18$ ) compared to other sub-groups of myositis (anti-Jo1: $n=10$, anti-SRP: $n=7$ and anti-HMGCR: $n=9$ ), we built and validated a decisional algorithm tree with classification and regression trees (CART) using the $\mathrm{R}$ software version 3.4.0. Potential biomarkers included in the CART were the percentages of CD8+ T-bet+ cells, CD8+ T-bet+ CD57+ cells, CD8+ T-bet+ CD27+ cells, CD8+ T-bet+ CD57+ CD27+ cells and CD8+ T-bet+ CD57- CD27+ cells. a) Decisional tree. $\mathrm{CV}$ was performed by dividing the data set into 10 parts. We randomly selected $70 \%$ of the data for the training set $(n=25)$, with the remainder assigned to the test set $(n=19)$, b) ROC curve based on the percentages of CD8+ T-bet+ cells of all myositis patients, showing sensitivity (Se), specificity (Sp), confidence interval (CI), area under curve (AUC) and $\mathrm{p}$ value for a cut-off value of CD8+ T-be+ cells $>51.51 \%$ and c) percentages of T-bet+ cells of all myositis patients within total CD8 cells. 
Fig 1

a) $\underline{\mathrm{CD} 3+} \quad \underline{\mathrm{CD} 4+} \quad \underline{\mathrm{CD} 8+} \quad \underline{\mathrm{CD} 11 \mathrm{~b}+} \quad \underline{\mathrm{CD} 56+}$

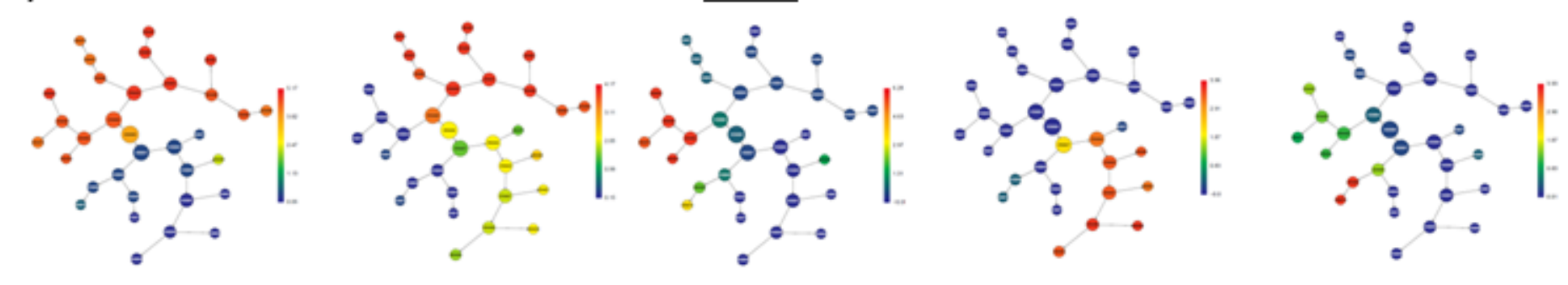

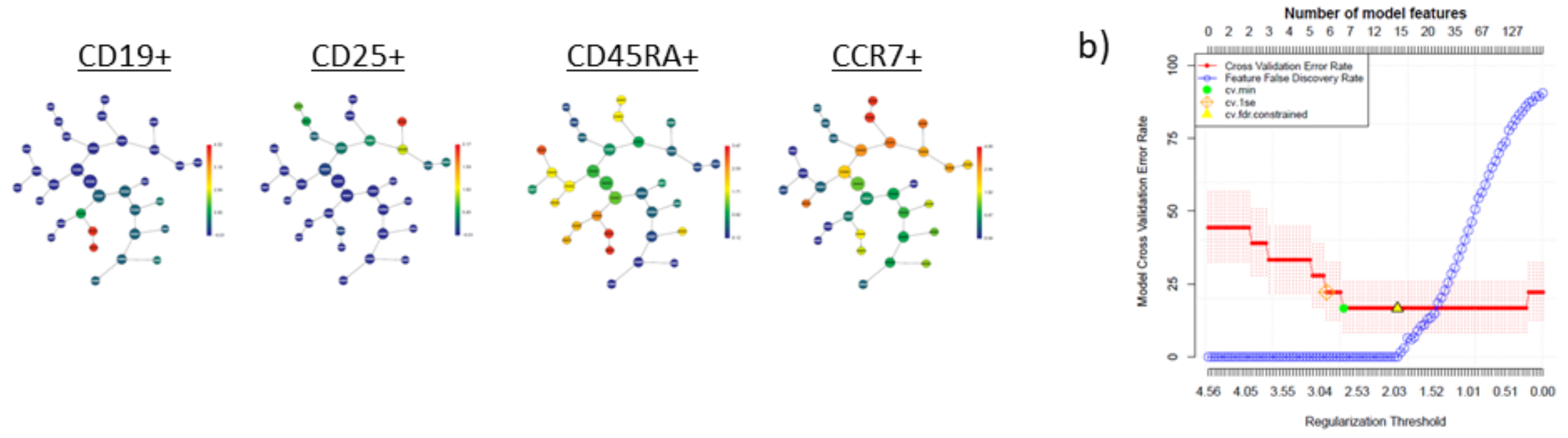

$\begin{array}{llllll}\text { c) } & \underline{\mathrm{CD} 27} & \underline{\mathrm{CD}} 57 & \underline{\mathrm{CD} 127} & \underline{\mathrm{CD} 28} & \underline{\mathrm{T}}\end{array}$

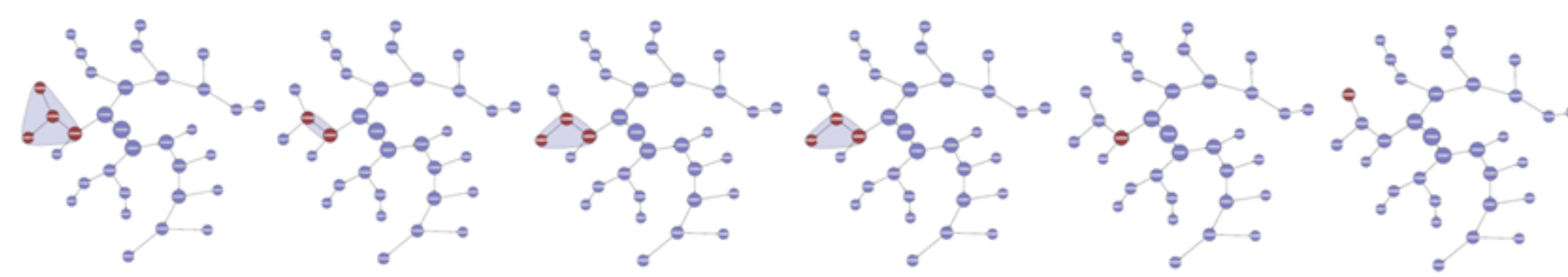


Fig 1

a) $\underline{\mathrm{CD} 3+} \quad \underline{\mathrm{CD} 4+} \quad \underline{\mathrm{CD} 8+} \quad \underline{\mathrm{CD} 11 \mathrm{~b}+} \quad \underline{\mathrm{CD} 56+}$

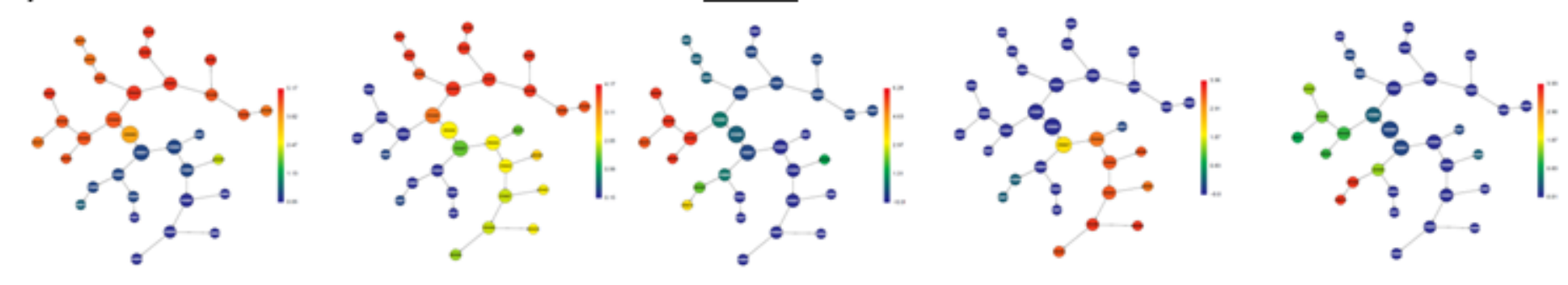

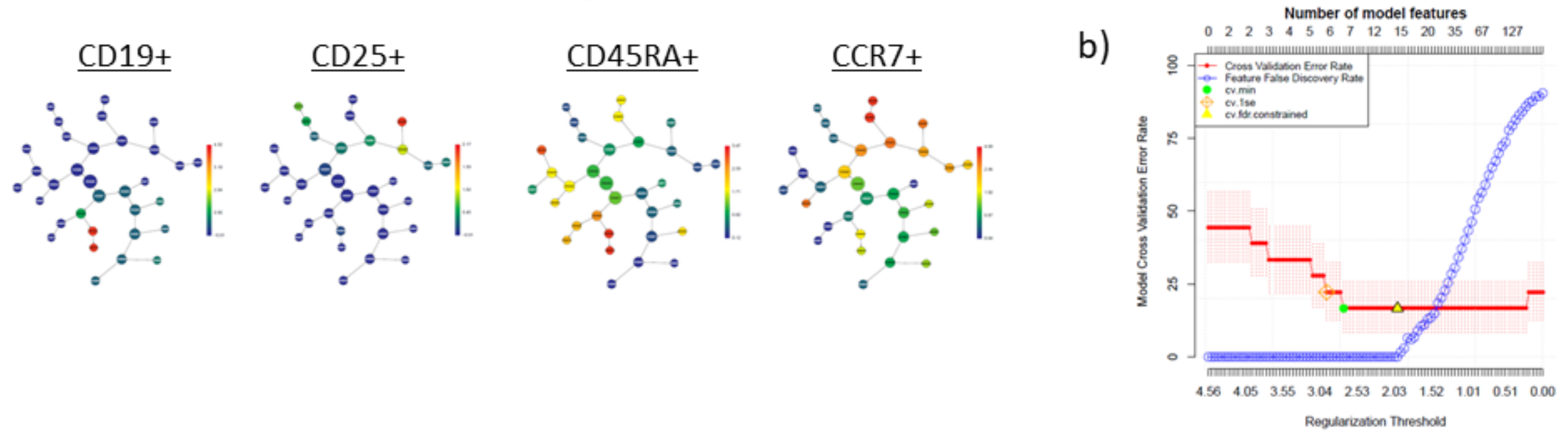

$\begin{array}{llllll}\text { c) } & \underline{\mathrm{CD} 27} & \underline{\mathrm{CD}} 57 & \underline{\mathrm{CD} 127} & \underline{\mathrm{CD} 28} & \underline{\mathrm{T}}\end{array}$

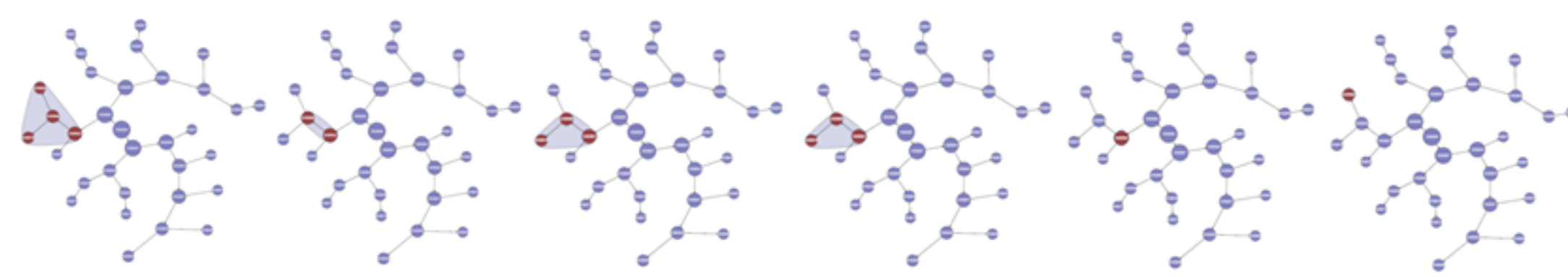


Fig 2
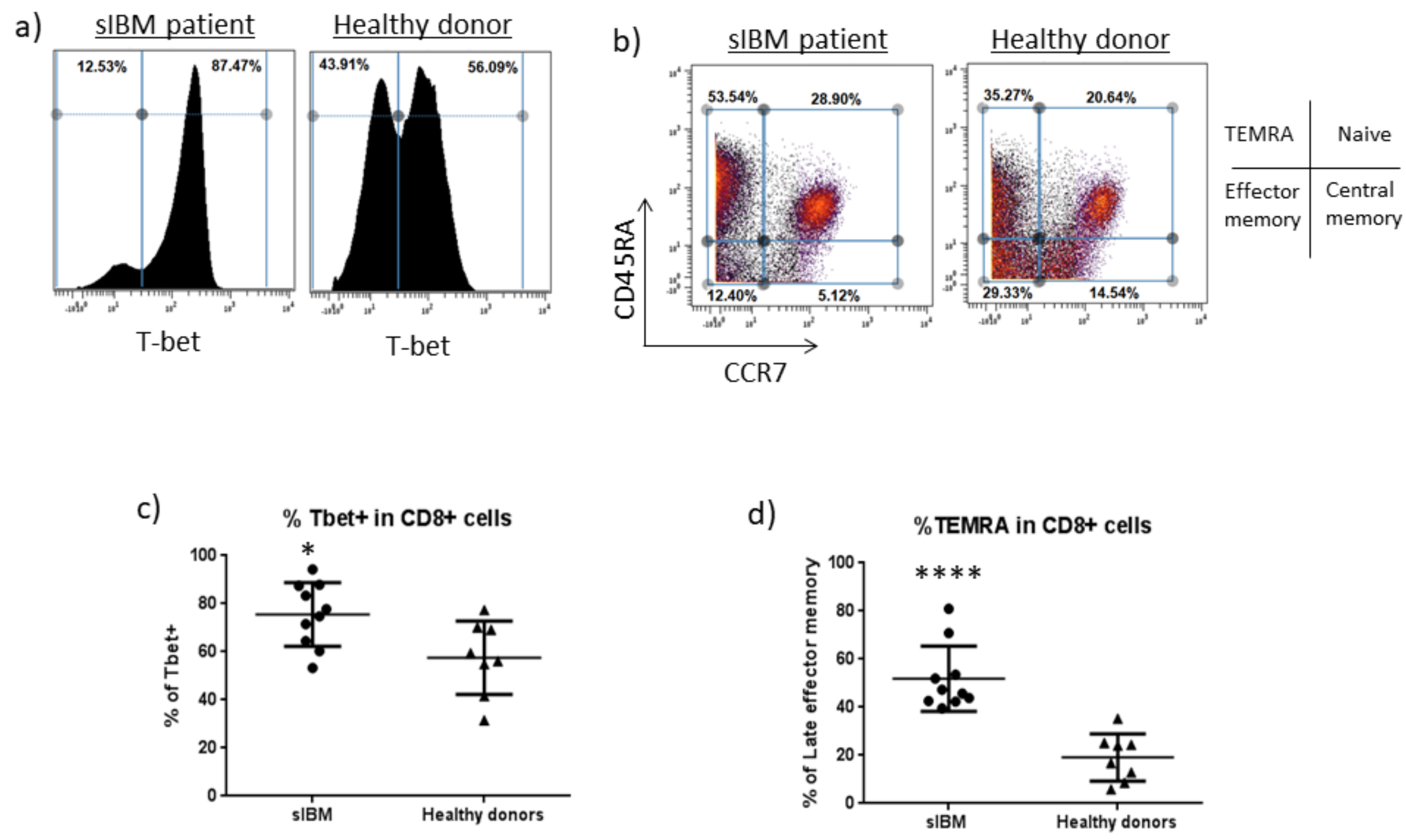
Fig 2
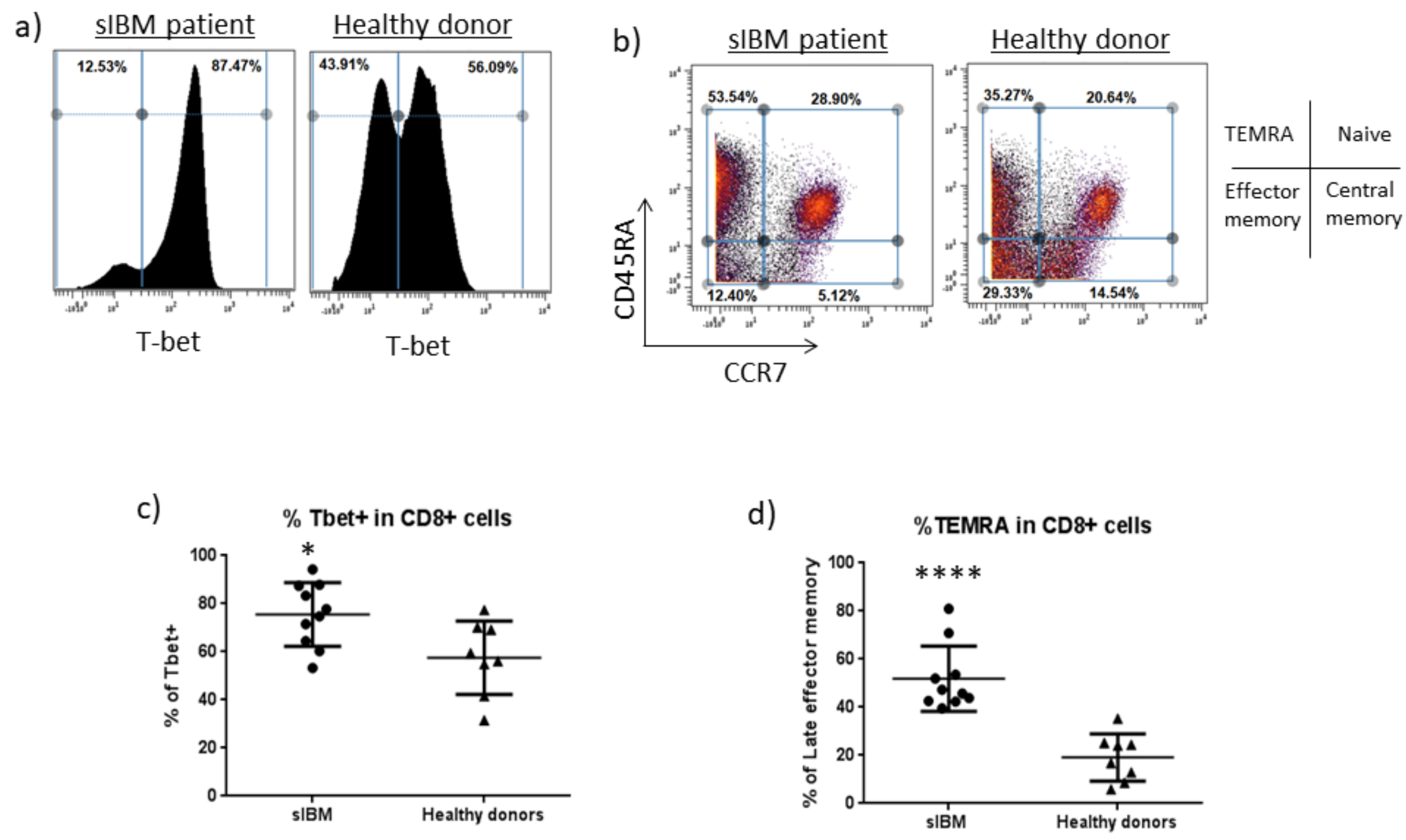
Fig 3

a)

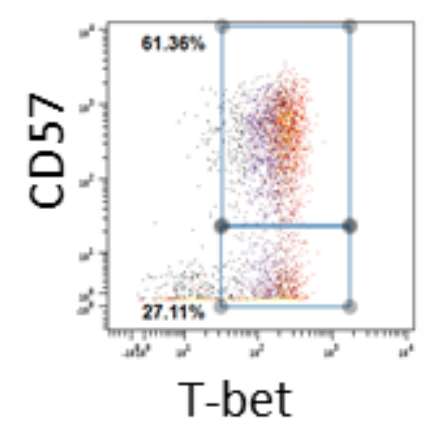

c)

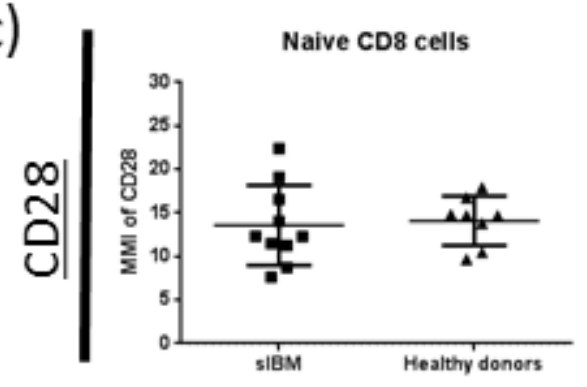

|

| b)
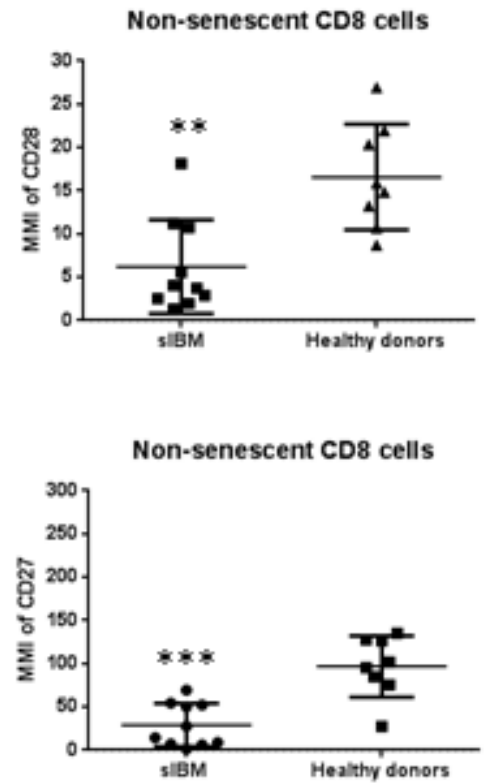

Non-senescent CD8 cells

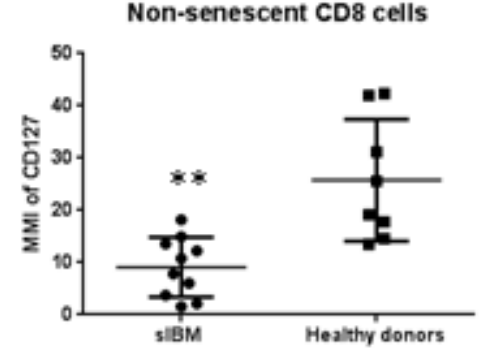

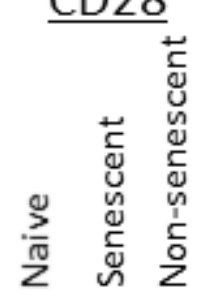
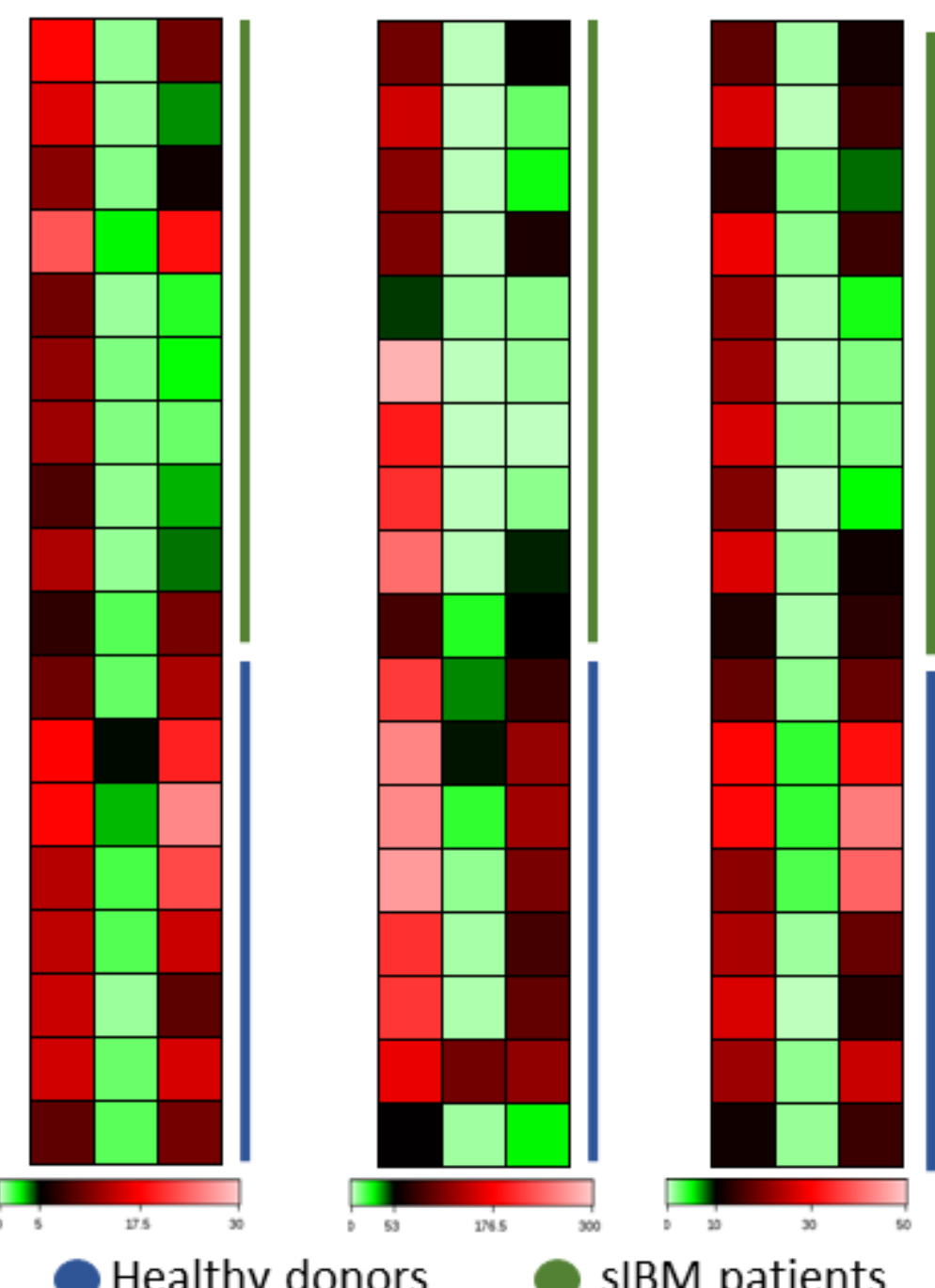

CD27

는

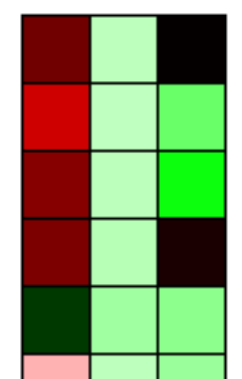

管

CD127
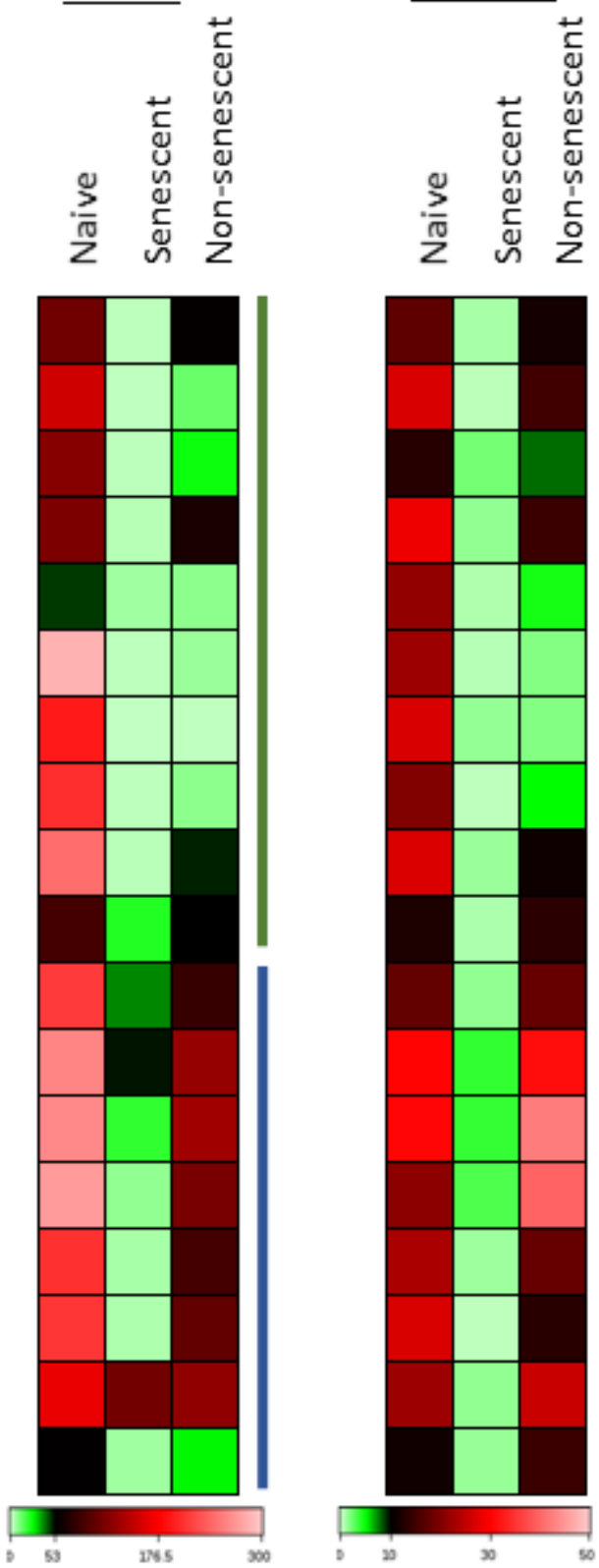

sIBM patients 
Fig 3

a)

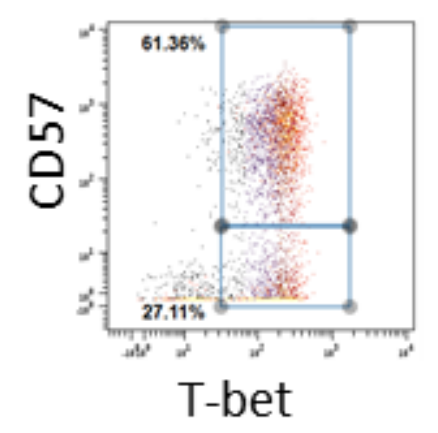

c)

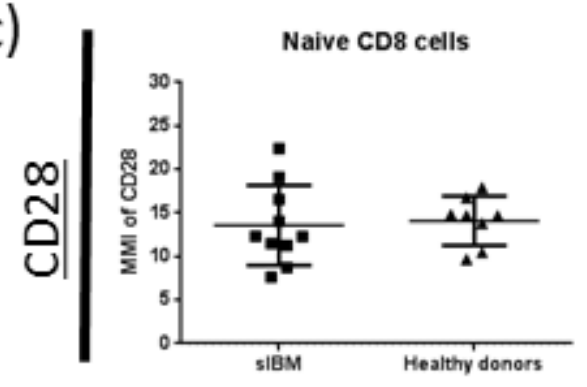

|

| b)
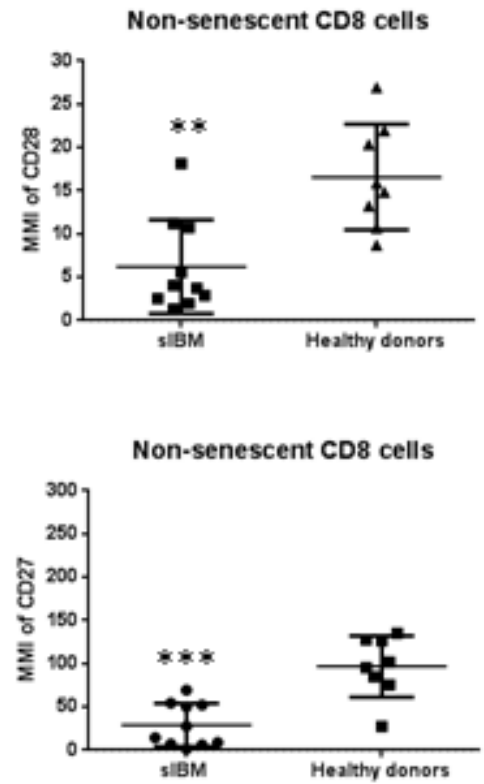

Non-senescent CD8 cells

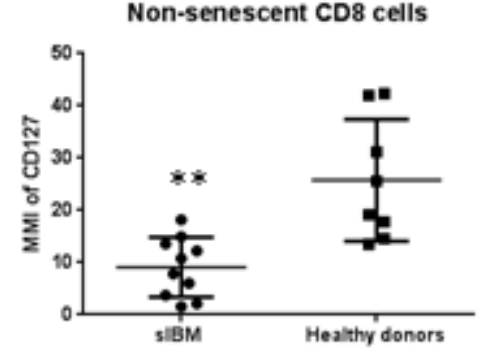

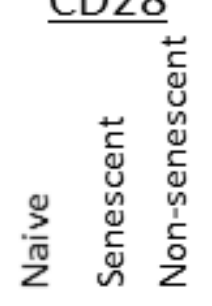
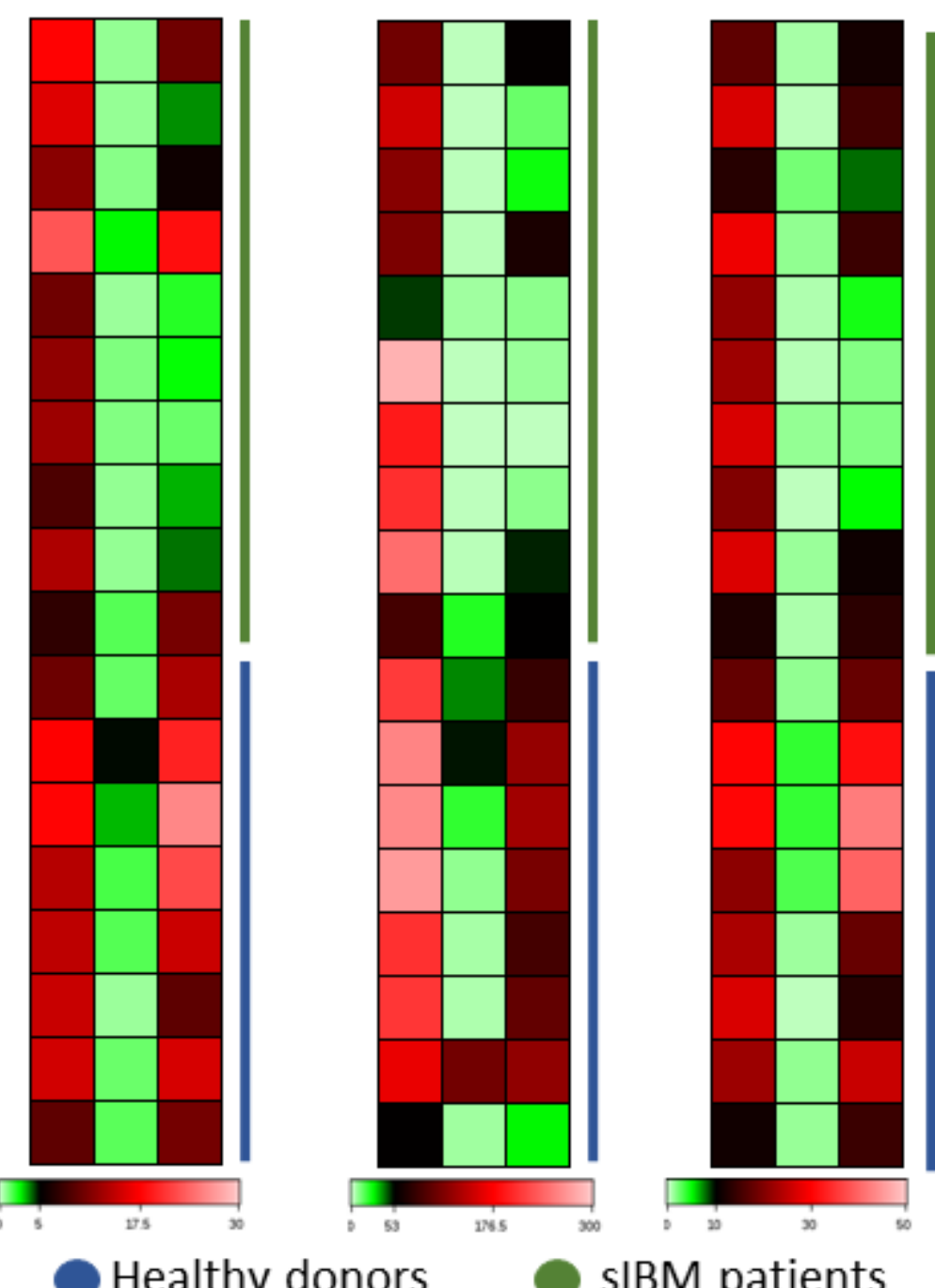

CD27

는

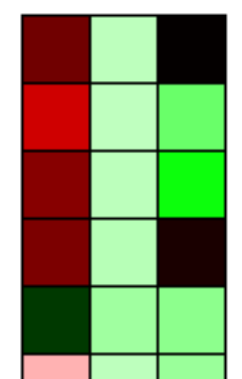

管

CD127
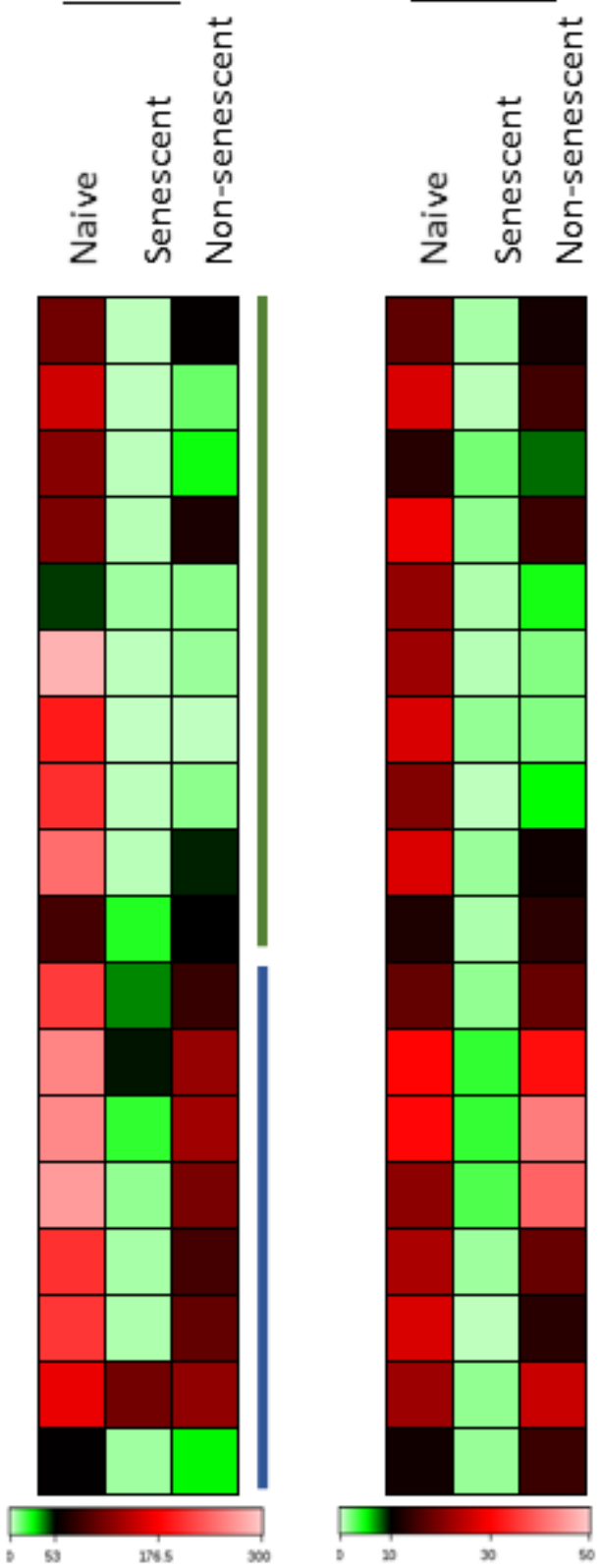

sIBM patients 


\section{Fig 4}

$\square \underline{C D 8+C D 38+}$
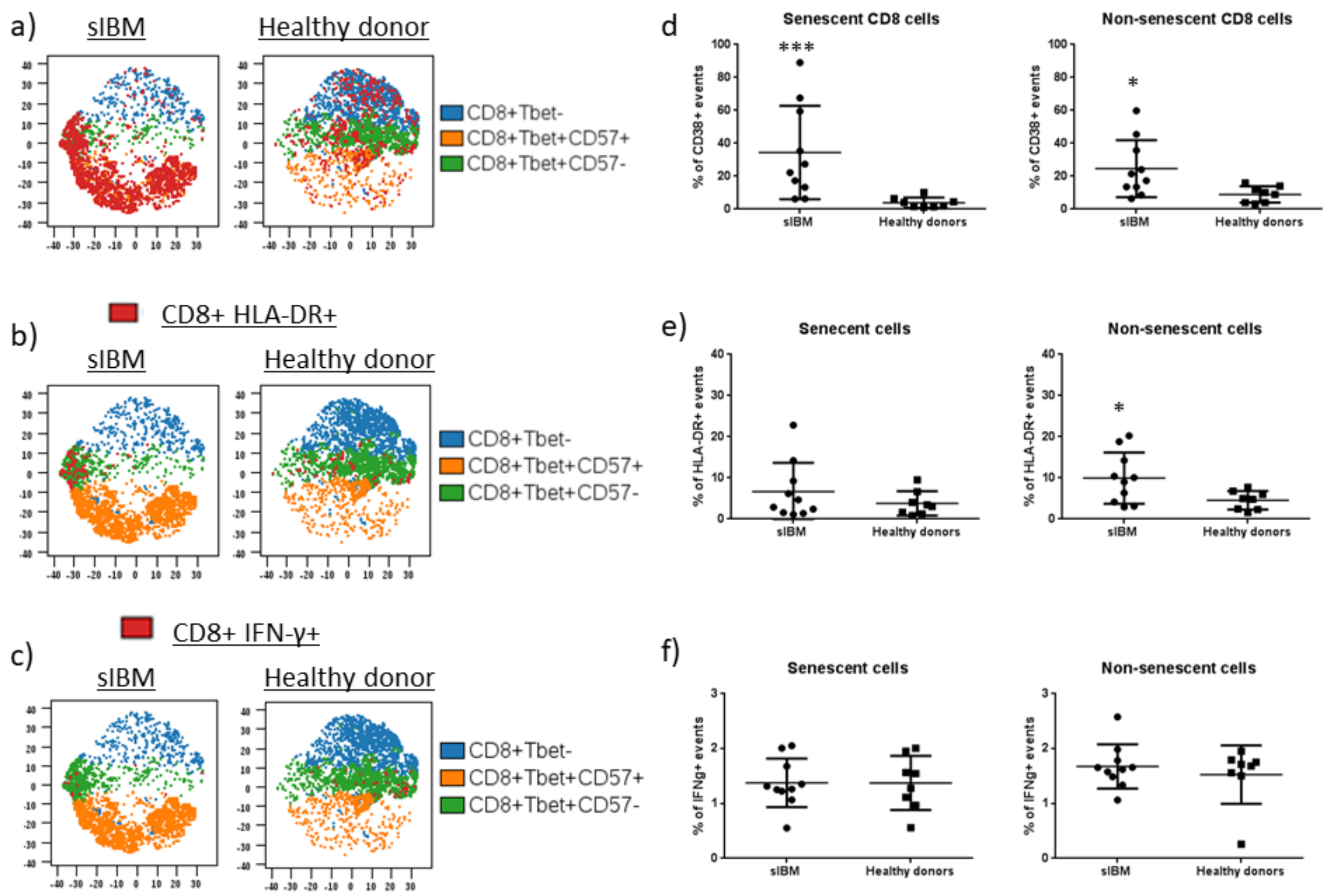


\section{Fig 4}

$\square \underline{C D 8+C D 38+}$
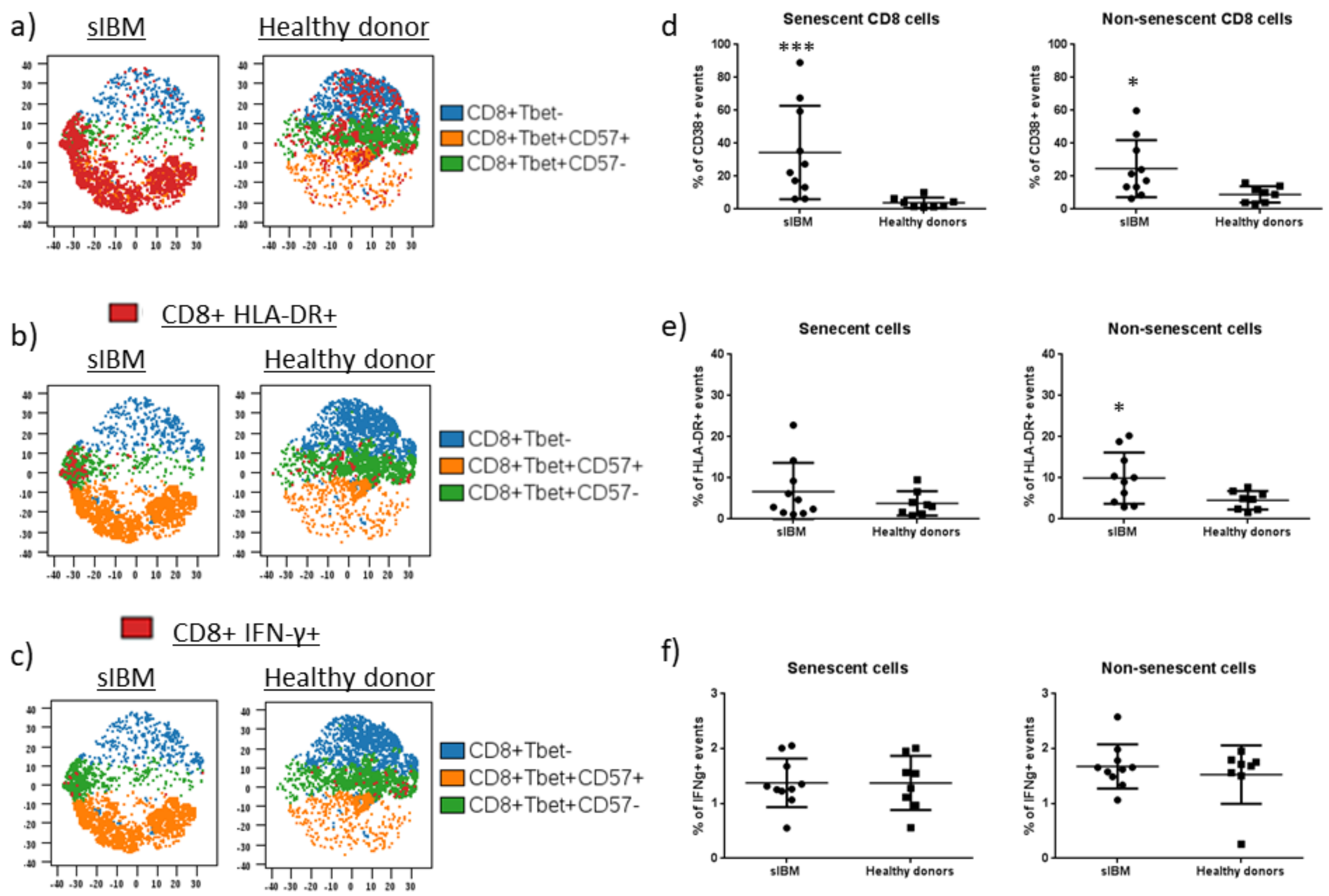


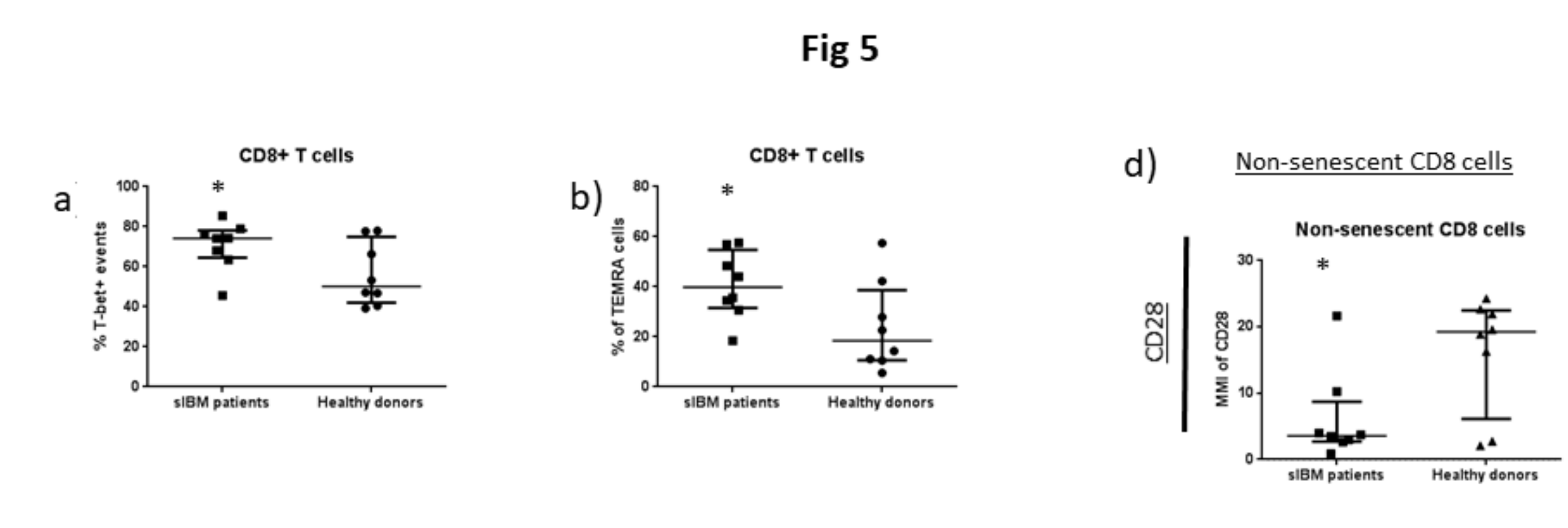

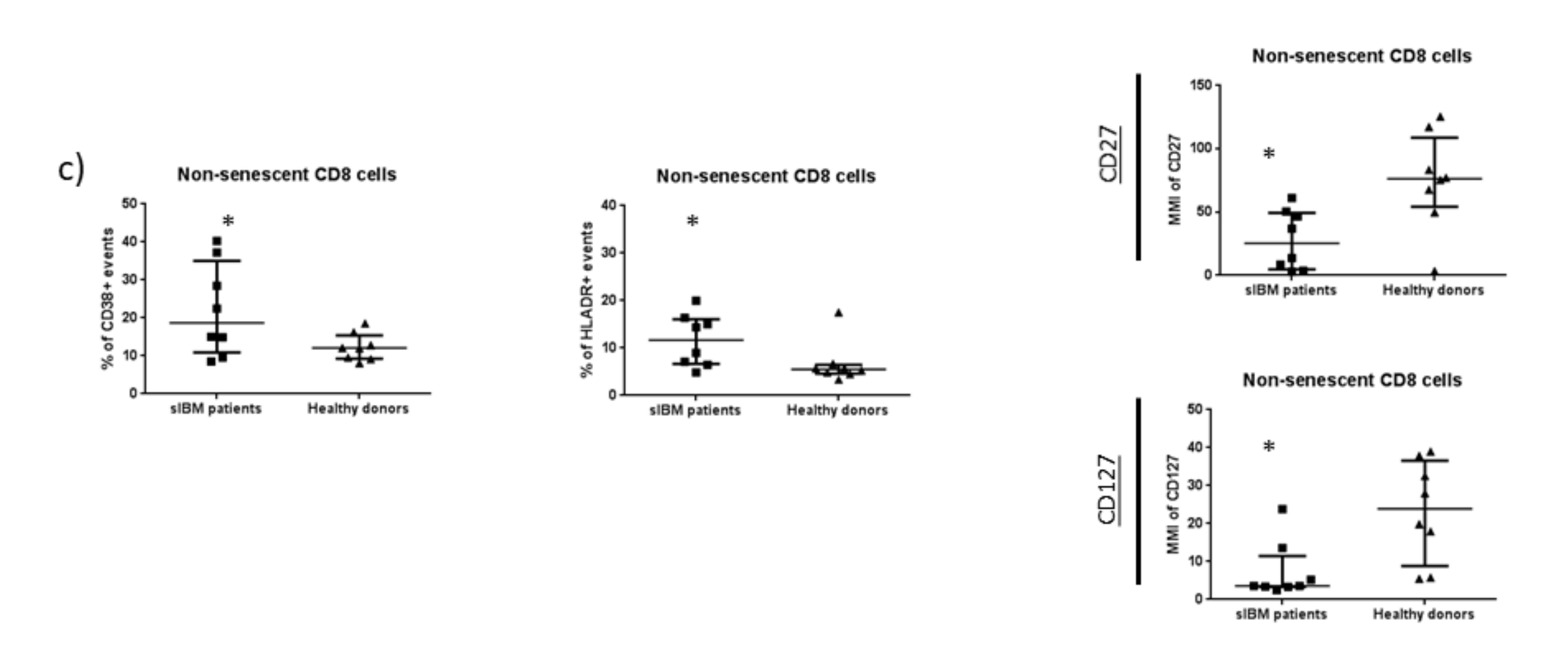




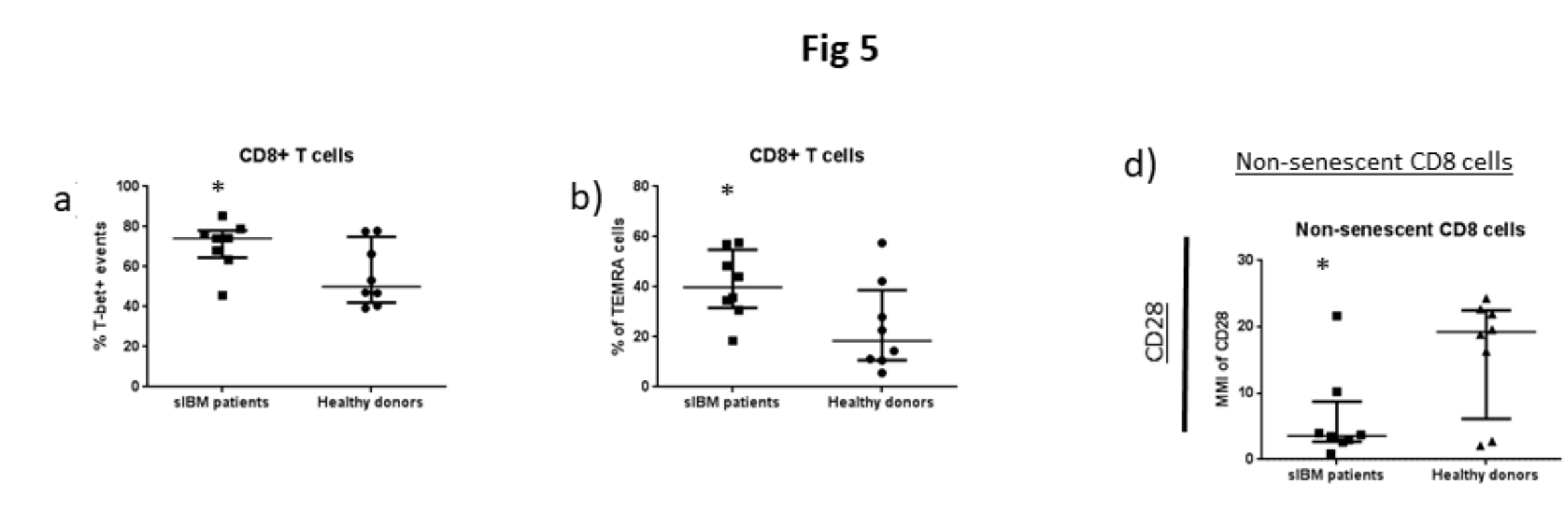

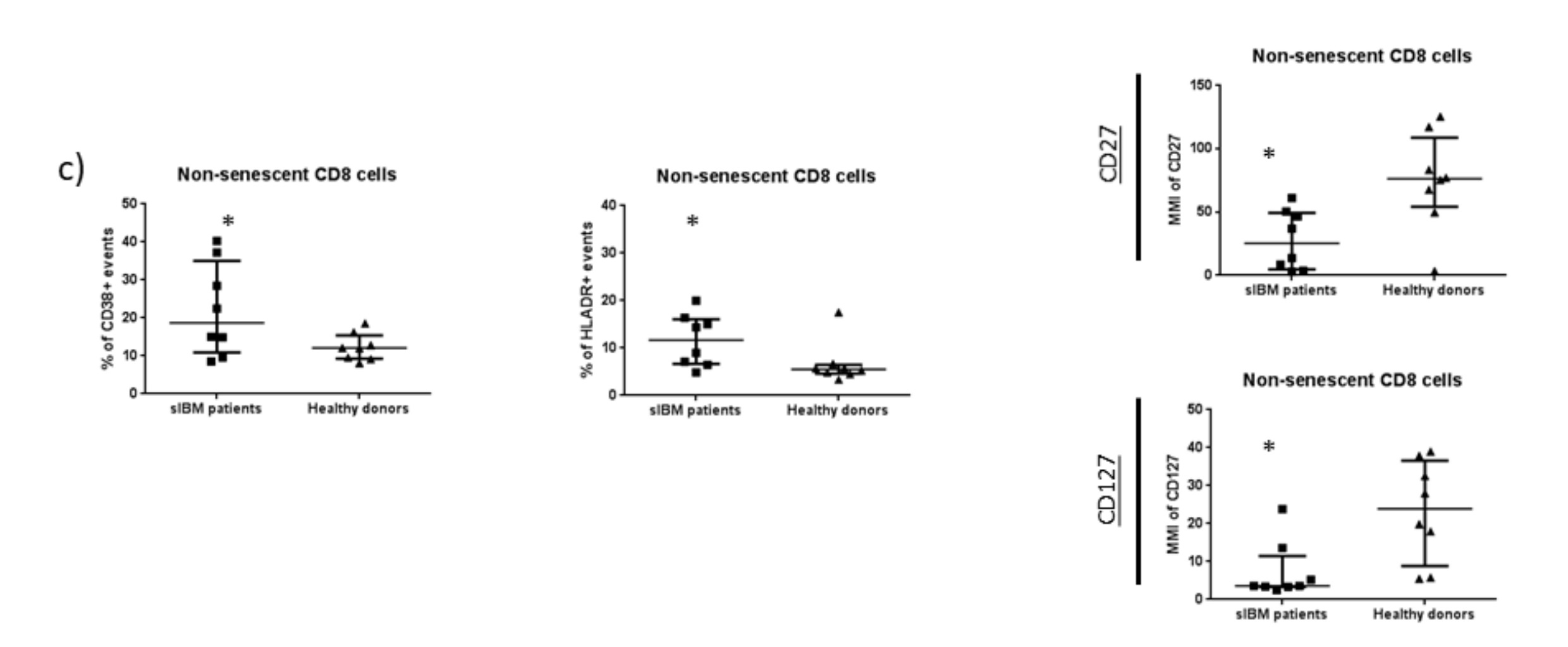


Fig 6

a)

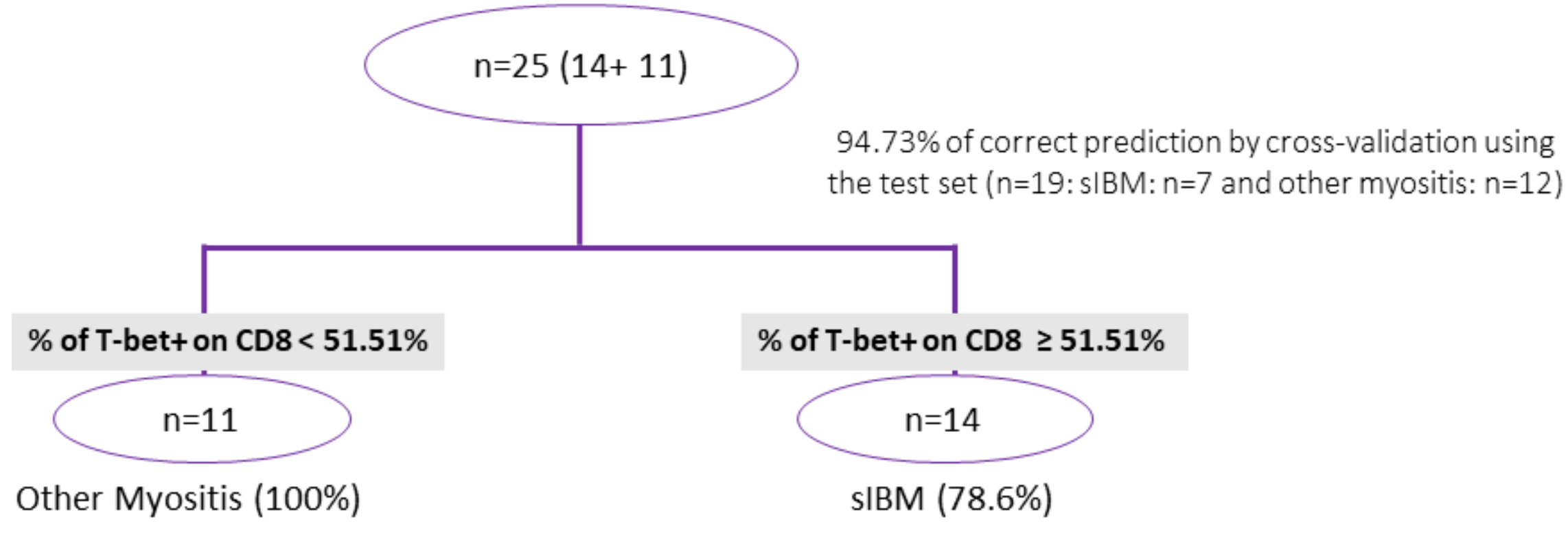

b)

CD8+ T-bet+ $T$ cells

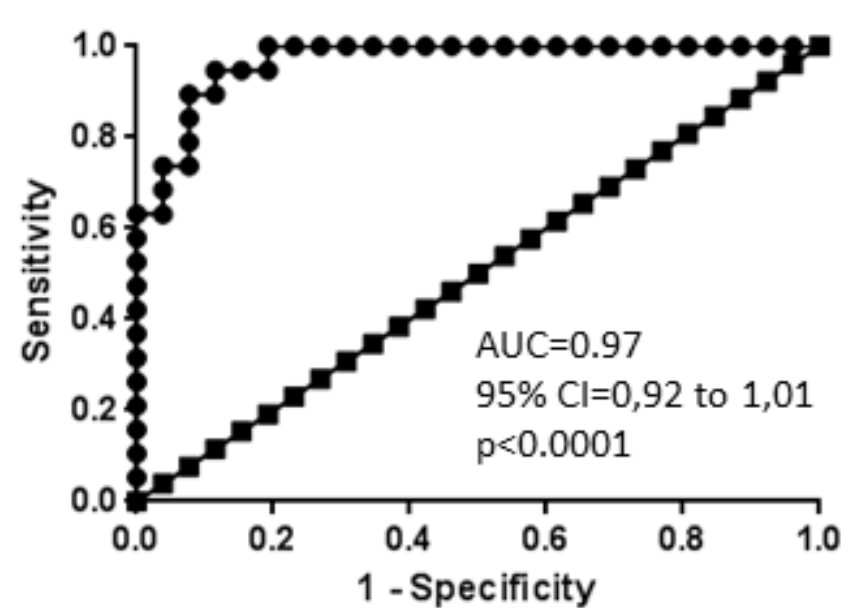

c)

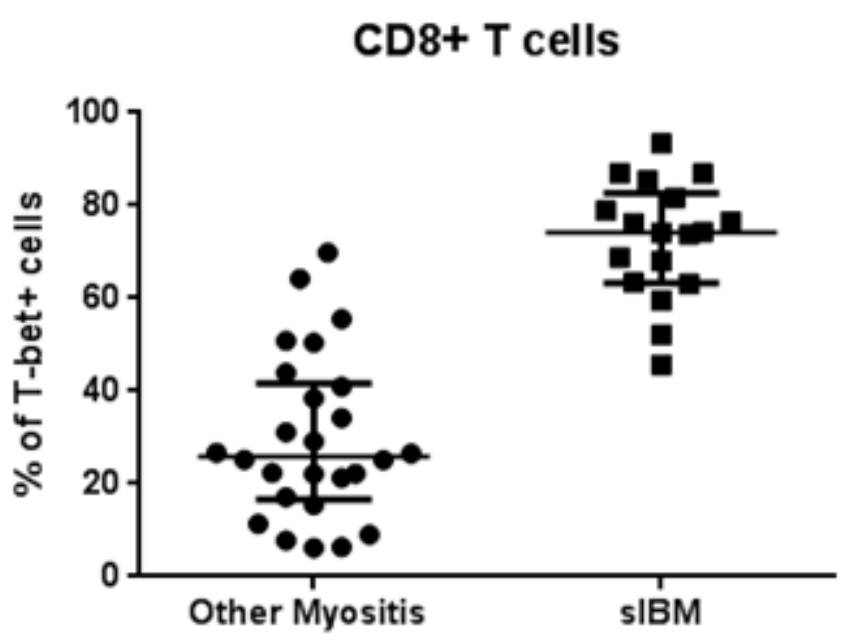

For frequencies of CD8+ T-bet+ $\mathrm{T}$ cells $>51.51 \%$, Se $=\mathbf{9 4 . 4 4 \% , S p = 8 8 . 4 6}$ 
Fig 6

a)

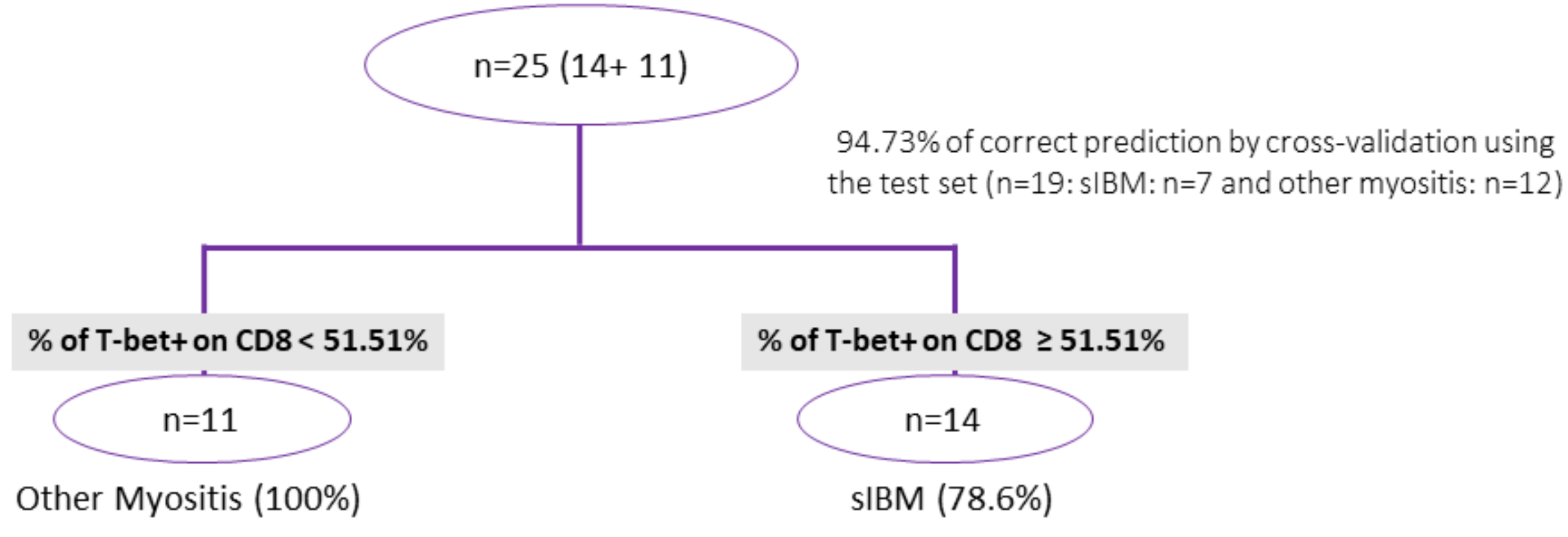

b)

CD8+ T-bet+ $T$ cells

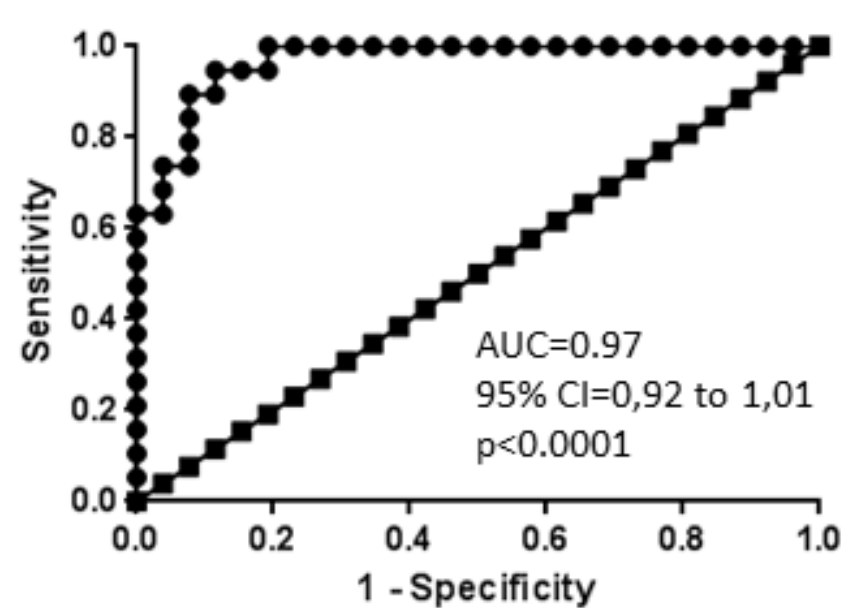

c)

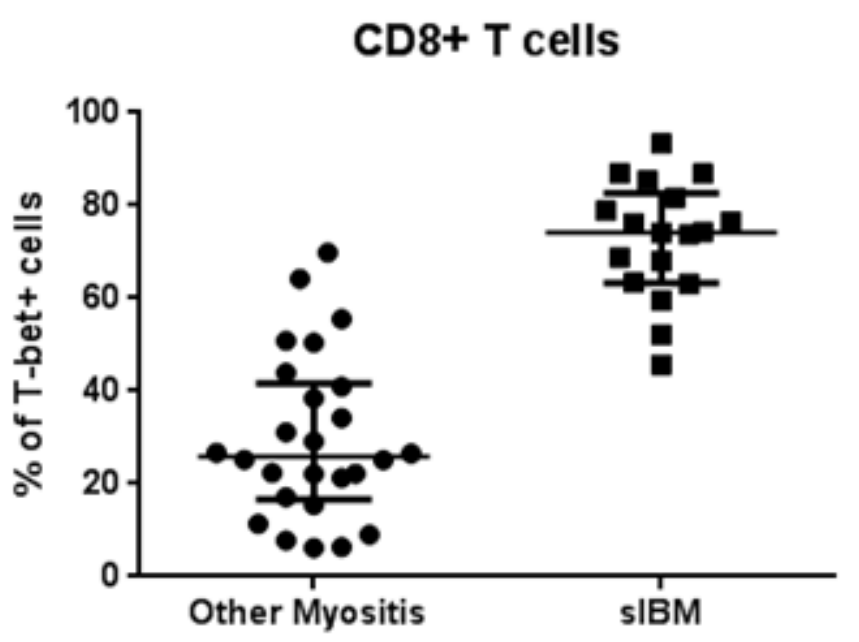

For frequencies of CD8+ T-bet+ $\mathrm{T}$ cells $>51.51 \%$, Se $=\mathbf{9 4 . 4 4 \% , S p = 8 8 . 4 6}$ 